\title{
High mobility group box 1 (HMGB1): a pivotal regulator of hematopoietic malignancies
}

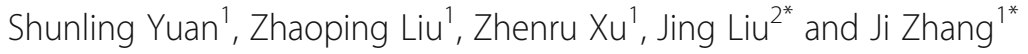

\begin{abstract}
High mobility group box 1 (HMGB1) is a nonhistone chromatin-associated protein that has been widely reported to play a pivotal role in the pathogenesis of hematopoietic malignancies. As a representative damage-associated molecular pattern (DAMP), HMGB1 normally exists inside cells but can be secreted into the extracellular environment through passive or active release. Extracellular HMGB1 binds with several different receptors and interactors to mediate the proliferation, differentiation, mobilization, and senescence of hematopoietic stem cells (HSCs). HMGB1 is also involved in the formation of the inflammatory bone marrow (BM) microenvironment by activating proinflammatory signaling pathways. Moreover, HMGB1-dependent autophagy induces chemotherapy resistance in leukemia and multiple myeloma. In this review, we systematically summarize the emerging roles of HMGB1 in carcinogenesis, progression, prognosis, and potential clinical applications in different hematopoietic malignancies. In summary, targeting the regulation of HMGB1 activity in HSCs and the BM microenvironment is highly beneficial in the diagnosis and treatment of various hematopoietic malignancies.
\end{abstract}

Keywords: High mobility group box 1 (HMGB1), Hematopoietic stem cells (HSCs), Bone marrow (BM) microenvironment, Inflammation, Chemoresistance

\section{Introduction}

High mobility group (HMG) is a non-histone chromosomebinding protein in eukaryotic cells that is named after its low molecular weight and high gel mobility [1]. According to the HMG molecular weight, structural similarity and DNA binding characteristics, HMG proteins are divided into three gene families: HMGA, HMGB, and HMGN. HMGB1, also known as amphoterin or HMG1, is the most abundant nonhistone nucleoprotein in the HMGB gene family. HMGB1 is also expressed to some extent in the cytoplasm, as it shuttles back and forth from the nucleus [2]. HMGB1 has dual functions as a nonhistone nucleoprotein and an

\footnotetext{
* Correspondence: jingliucsu@hotmail.com; zhang_ji001@hotmail.com ${ }^{2}$ Hunan Province Key Laboratory of Basic and Applied Hematology, Molecular Biology Research Center \& Center for Medical Genetics, School of Life Sciences, Central South University, Changsha 410078, Hunan, China 'Department of Clinical Laboratory, The First Affiliated Hospital, University of South China, Hengyang 421001, Hunan, China
}

extracellular inflammatory cytokine. Intracellular HMGB1 is extensively bound to DNA and involved in transcriptional regulation, DNA replication and repair, telomere maintenance, and nucleosome assembly. Extracellular HMGB1 is passively released by necrotic tissue or stressed cells or actively secreted. As a chemokine or cytokine, it binds to pattern recognition receptors (PRRs) to play the role of a damage-associated molecular pattern (DAMP) [3].

\section{Overview of HMGB1}

The biological structure of HMGB1

The HMGB1 gene is located on chromosome 13q12 and includes five exons and four introns. The TATA box promoter of the HMGB1 gene contains binding sites for several transcription factors, such as activator protein 1 (AP1), and a silencing element [4]. Human HMGB1 protein is a highly conserved nuclear protein consisting of

(c) The Author(s). 2020 Open Access This article is licensed under a Creative Commons Attribution 4.0 International License, which permits use, sharing, adaptation, distribution and reproduction in any medium or format, as long as you give appropriate credit to the original author(s) and the source, provide a link to the Creative Commons licence, and indicate if changes were made. The images or other third party material in this article are included in the article's Creative Commons licence, unless indicated otherwise in a credit line to the material. If material is not included in the article's Creative Commons licence and your intended use is not permitted by statutory regulation or exceeds the permitted use, you will need to obtain permission directly from the copyright holder. To view a copy of this licence, visit http://creativecommons.org/licenses/by/4.0/. The Creative Commons Public Domain Dedication waiver (http://creativecommons.org/publicdomain/zero/1.0/) applies to the data made available in this article, unless otherwise stated in a credit line to the data. 
215 amino acids with a molecular weight of approximately $30 \mathrm{kD}$. Structurally, HMGB1 is divided into three functional regions (Fig. 1): A-box (9-79 aa), B-box (89162 aa), and acidic C-terminus (186-215 aa). The A-box and B-box are composed of 80-90 amino acid residues, with similar amino acid repeats and nonspecific DNA binding sites; the B-box is a functional structural region that causes an inflammatory response [5]. However, the A-box has a certain antagonistic effect on the B-box [6]; the acidic $\mathrm{C}$-terminus containing aspartic acid and glutamic acid is mainly involved in regulating the binding affinity between HMGB1 and DNA, and mediates gene transcription and chromosome derotation [7]. The Nterminus of HMGB1 (6-12 aa) contributes to heparinbinding activity. After binding to HMGB1, heparin impacts the spatial conformation of HMGB1, reduces the affinity of HMGB1 for its receptor, and inhibits its proinflammatory activity $[8,9]$. The B-box domain has two crucial binding sites for Toll-like receptor 4 (TLR4) and receptor for advanced glycation end products (RAGE), which regulate the release of proinflammatory cytokines. The RAGE binding site of HMGB1 is located between amino acid residues 150 and 183, and the 20 amino acids of the TLR4 binding site (89--108 aa) are the minimal sequence necessary to induce cytokine activity $[10,11]$. Although HMGB1 is an evolutionarily conserved multifunctional protein, the biological function of HMGB1 depends on its modifications, cellular location, redox state, and binding partners.

\section{Posttranslational modification of HMGB1}

The HMGB1 protein shuttles between the nucleus and cytoplasm because it contains two nuclear localization sequences (NLSs) and two putative nuclear export signals (NESs). HMGB1 interacts with the nuclear receptor chromosome-region maintenance-1 (CRM-1), which is a nuclear transport receptor involved in the export of leucine-rich NES proteins and is then released from the nucleus into the cytoplasm [12]. The conserved lysine residues in the NLSs are sensitive to acetylation and can activate nuclear exclusion and HMGB1 translocation [13-15]. In addition to acetylation, HMGB1 is regulated by extensive posttranslational modifications (PTMs) including methylation, phosphorylation, ADP-ribosylation, glycosylation, and ubiquitination. These PTMs redirect it toward secretion and modulate its interactions with DNA and other proteins [16]. Then, the oxidation of extracellular HMGB1 determines its bioactivity in mediating inflammation and innate immune responses.

\section{Acetylation}

HMGB1 is usually located in the cell nucleus. Since HMGB1 lacks a secretory signal peptide and does not traverse the ER-Golgi system, the secretion of this

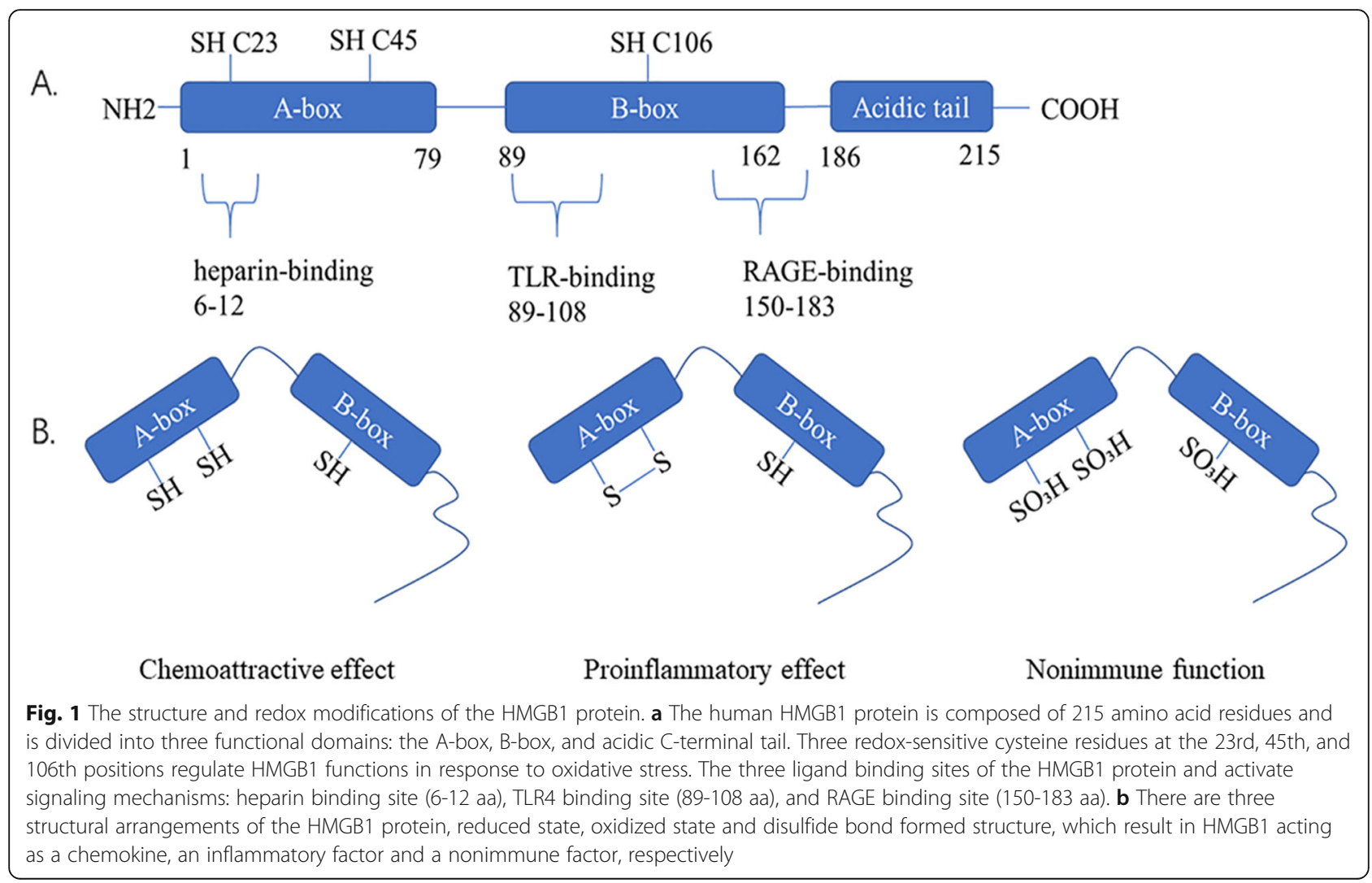


nuclear protein seems to require a tightly controlled relocation program [17]. Numerous studies have proven that acetylation regulates the cytoplasmic accumulation of HMGB1. In the inflammatory response, HMGB1 is extensively acetylated in monocytes and macrophages upon activation with lipopolysaccharide; moreover, enhanced hyperacetylation of HMGB1 in resting macrophages causes HMGB1 translocation to the cytoplasm. Cytosolic HMGB1 is concentrated by default into secretory lysosomes and secreted when monocytic cells receive the appropriate second signal. $\mathrm{P300/CBP-associ-}$ ated factor (PCAF), CREB-binding protein (CBP), and histone acetyltransferase p300 (p300) play important roles in HMGB1 acetylation [13]. Mass spectrometric analysis revealed that type 1 interferon (IFN)-stimulated activation of JAK/signal transducer and activator of transcription 1 (STAT1) could induce HMGB1 acetylation and translocation from the nucleus to the cytoplasm [18].

\section{Methylation}

Besides acetylation, it has been demonstrated that the monomethylation of lysine-42 in HMGB1 isolated from neutrophils regulates its relocalization from the nucleus to the cytoplasm. Methylated HMGB1 is mostly located in the cytoplasm of neutrophils, while unmethylated HMGB1 is present in the nucleus. Because methylation leads to conformational changes in the HMGB1 protein, the possible mechanism by which methylation controls distribution is that methylation of Lys- 42 alters the conformation of the A-box, thereby impairing its ability to bind to DNA. Then, methylated HMGB1 passively diffuses from the nucleus into the cytoplasm [19].

\section{Phosphorylation}

Phosphorylation is also important in blocking HMGB1 reentry to the nucleus and accumulating in the cytoplasm. Earlier reports found that HMGB1 isolated from lamb thymus could be phosphorylated by calcium/phospholipiddependent protein kinase but not by cAMP-dependent protein kinase [20]. Recently, a study demonstrated that HMGB1 was phosphorylated in RAW264.7 cells and human monocytes after treatment with tumor necrosis factor alpha (TNF- $\alpha$ ) or okadaic acid (OA, a phosphatase inhibitor), resulting in the transport of HMGB1 to the cytoplasm and eventual secretion. The six possible phosphorylation sites are Ser-34, Ser-38, Ser-41, Ser-45, Ser-52, and Ser-180, which are mainly around NLS1 and NLS2 [14]. Moreover, phosphorylation promotes HMGB1 relocation to the cytoplasm and subsequent secretion through protein kinase C-regulated calcium-dependent mechanisms [21].

\section{ADP-ribosylation}

ADP-ribosylation reactions add one or more ADP-ribose moieties to a protein by ADP-ribosyl transferases, and are classified into four groups: mono-ADP-ribosylation, polyADP-ribosylation, ADP-ribose cyclization, and the formation of $O$-acetyl-ADP-ribose. Hyper ADP-ribosylation of HMGB1 downregulates gene transcription since ADPribosylation is generally inversely related to transcription. Recently, the poly-ADP-ribosylation of HMGB1 was found to facilitate its acetylation and promoted HMGB1 translocation-associated chemotherapy-induced autophagy in leukemia cells [22]. The activation of SIRT6 and PARP1 is required for chemotherapy-induced ADPribosylation of HMGB1 and mediates HMGB1 translocation [23]. Hyperpoly-ADP-ribosylation of HMGB1 enhances the inhibition of efferocytosis, but a lack of intracellular HMGB1 leads to excessive activation and damage of PARP1 [24, 25]. Hence, HMGB1 and PARP1 can regulate cell death by ADP-ribosylation.

\section{Glycosylation}

HMGB1 $N$-glycosylation plays a prerequisite role in nucleocytoplasmic translocation and extracellular secretion. HMGB1 was reported to be $N$-glycosylated at Asn-37 and alternatively at Asn-134/135 residues, which determines HMGB1 nucleocytoplasmic transport, extracellular secretion, and protein stability. Moreover, two $\mathrm{N}$-glycosylations at Asn-37 and Asn-134 were further identified as the consensus motifs of Asn-Xxx-Ser/Thr, whereas recombinant HMGB1 protein was glyecosylated at the noncelassical consensus residue Asn-135 in both HEK293T and insect cells [26].

\section{Ubiquitination}

Protein ubiquitination participates in many basic cellular processes, such as proteolysis, DNA repair, and DNA transcription, in response to diverse stimuli [27]. Ubiquitin $(\mathrm{Ub})$ is an evolutionarily conserved protein that posttranslationally marks proteins for degradation [28]. It has been reported that the enhanced level of HMGB1 ubiquitination may be the causative factor in multiple myeloma (MM). Moreover, MALAT-1 knockdown promotes the degradation of HMGB1 at the posttranslational level by increasing the ubiquitination of HMGB1 in MM cells [29]. It was also found that lycorine downregulates HMGB1 by promoting HMGB1 ubiquitination to inhibit autophagy in MM cells [30]. This finding suggests that ubiquitin proteasome system (UPS) inhibitors could have great therapeutic potential for MM treatment in the clinic.

\section{Oxidation}

HMGB1 contains three cysteine residues at positions 23rd, 45th, and 106th that are susceptible to redox-dependent modifications. When released into the extracellular space, HMGB1 is initially in a fully reduced state (fr-HMGB1) but becomes disulfide-HMGB1 (ds-HMGB1) due to the 
oxidative environment. When exposed to a large amount of reactive oxygen species (ROS) from activated leukocytes, HMGB1 can be sulfonated (ox-HMGB1). These three different extracellular HMGB1 redox states play distinct roles in inflammation. fr-HMGB1 binds to CXC motif ligand (CXCL) 12 and stimulates chemoattraction via the $\mathrm{CXC}$ motif chemokine receptor type 4 (CXCR4) [31]. Under normal circumstances, the majority of intracellular HMGB1 is fully reduced, which maintains structural integrity and protects against terminal oxidation by ROS [32]. Reduced cysteine residues also make HMGB1 a chemoattractant that can recruit leukocytes and promote tissue regeneration [33, 34]. ds-HMGB1 has a disulfide bond between cysteine 23 and cysteine 45 , which elicits inflammatory responses and cytokine-inducing activity through TLR4/myeloid differentiation factor 2 (MD-2) [35]. In ox-HMGB1, the cysteines are fully oxidized or C-106 is oxidized, preventing HMGB1 from having cytokine or chemotactic activity. Furthermore, ox-HMGB1 participates in the resolution of inflammation in highly acidic conditions [36]. The redox status of HMGB1 in terms of location and release directly influences its extracellular activity, such as immunity and inflammation [32].

\section{The release mechanism of HMGB1}

There are two mechanisms for releasing HMGB1 into the extracellular environment: passive release and active release (Fig. 2). In response to infection and injury, HMGB1 can be actively secreted from activated immune cells or passively released from damaged or necrotic cells and transferred outside the cell [37, 38]. Active release of HMGB1 from macrophages or monocytes requires a proinflammatory stimulus that could cause an immune response. Active HMGB1 release promotes neutrophil recruitment and macrophage release of proinflammatory cytokines, such as TNF- $\alpha$ and interleukin-6 (IL-6) and dendritic cell (DC) activation [39]. HMGB1 can be passively secreted from the nuclei of necrotic cells and damaged cells and then triggers inflammatory responses by functioning as necrotic cell death markers [36].

\section{Extracellular HMGB1 receptors and signaling pathways} Once released from the cells, HMGB1 binds to cellsurface receptors, inducing a reaction as a prototypical DAMP. Classic HMGB1 receptors include RAGE, TLRs (TLR2, TLR4, and TLR9), CXCR4, and T cell immunoglobulin mucin-3 (TIM-3) [40, 41].

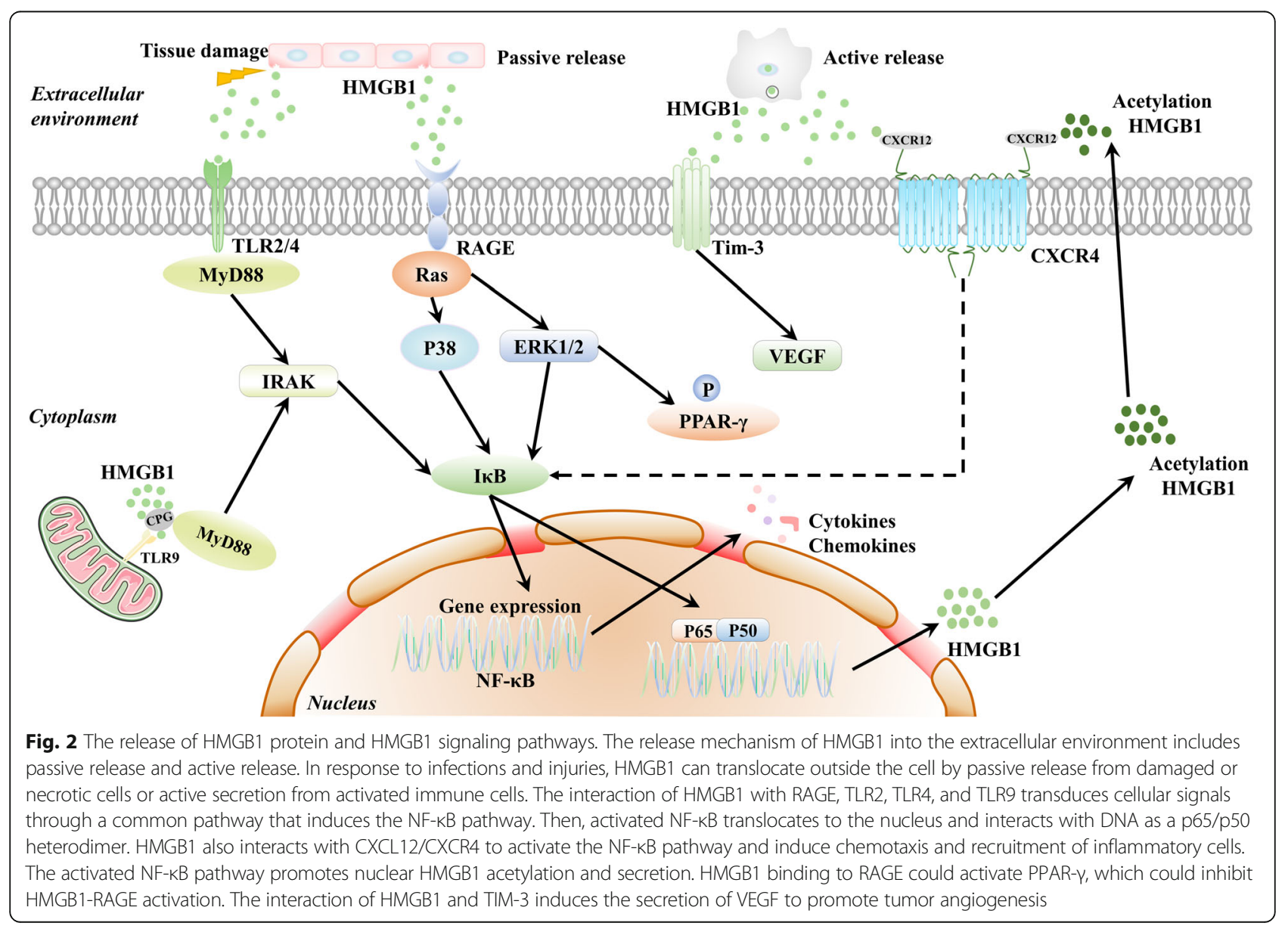




\section{RAGE}

In 1995, it was first discovered that RAGE bound with HMGB1 [42]. RAGE is a member of the immunoglobulin superfamily and is a transmembrane receptor that binds to advanced glycation end products. RAGE contains one extracellular immunoglobulin variable $(\operatorname{IgV})$ domain for ligand addition, two constant " $\mathrm{C}$ "-type extracellular domains, a transmembrane spanning domain, and a 43-amino acid cytosolic tail for RAGE-mediated intracellular signaling [43]. Several studies claimed that RAGE is an essential receptor for HMGB1-induced cell autophagy, immune responses, adhesion, and migration, which is carried out through the mitogen-activated protein kinase (MAPK), nuclear factor (NF)- $\mathrm{BB}$, and mammalian/mechanistic target of rapamycin (mTOR) signaling pathways $[44,45]$. The proinflammatory effect of the HMGB1-RAGE axis is significantly associated with the NF- $\mathrm{KB}$ pathway, which involves extracellular signal-regulated kinase 1 and 2 (ERK1/2), and p38 MAPK. Then, activated NF- $\mathrm{BB}$ translocates to the nucleus and interacts with DNA as a p65/p50 heterodimer, which enhances proinflammatory cytokine expression [46-48]. Although the role of the HMGB1-RAGE axis in cancer is not completely clear, HMGB1 is critical for directly activating RAGE or activating peroxisome proliferator-activated receptor gamma (PPAR- $\gamma$ ) pathway, and inhibiting HMGB1-RAGE activation, which might be a beneficial cancer therapeutic strategy [49].

\section{TLRs}

TLRs are PRRs that consist of extracellular leucinerich repeats (LRRs) and a cytoplasmic Toll/interleukin-1 receptor (TIR) domain. The ligand binds to LRRs and activates signal transduction pathways through TIR domains with conserved adaptor molecules. Most TLRs signal through MyD88, while TLR3 utilizes TRIF, and TLR4 is the only receptor that utilizes both MyD88 and TRIF. TLRs play a critical role in the promotion of macrophage activation, cytokine release, and tissue damage. The underlying mechanism involves the MyD88-dependent and MyD88independent pathways and activation of downstream factors such as MAPK and IFN regulatory factors [50, 51]. HMGB1 can interact with TLRs and then induce a series of cytokines and chemokines by triggering relevant signal transduction pathways [52]. In addition, HMGB1 forms complexes with partner molecules and then acts via the partner's receptor [53]. HMGB1 binds to CpG-DNA and promotes its interaction with the DNA-sensing TLR9 receptor [54]. Extracellular HMGB1 activates RAGE or TLR4 and forms a heterocomplex with CXCL12 that strongly activates CXCR4, promoting inflammatory and pain signals $[31,55]$.

\section{CXCR4}

CXCR4 was known as a coreceptor that supported T lymphocyte-tropic HIV infection of permissive cells in 1996 [56]. CXCR4 is a G-protein-coupled seven-transmembrane receptor (GPCR) that is widely expressed in CD34 hematopoietic stem cells (HSCs), lymphocytes, monocytes and macrophages, endothelial and epithelial cells, and cancer cells [57]. CXCL12 (stromal cell-derived factor-1, SDF-1), the CXCR4 ligand, is expressed by hematopoietic cells in the bone marrow (BM), facilitating the adhesion and survival of malignant clones. The CXCL12/CXCR4 axis is involved in tumor progression, angiogenesis, metastasis, and survival by activating multiple signaling pathways, such as ERK1/2, ras, p38 MAPK, PLC/MAPK, and SAPK/JNK $[58,59]$. CXCL12/CXCR4 antagonists have shown encouraging results in reducing the enhanced survival and proliferation of leukemia cells and sensitizing leukemia cells to chemotherapy [60, 61]. During inflammation or tissue damage, extracellular fr-HMGB1 exerts chemotactic activity and enhances leukocyte recruitment by forming a heterocomplex with CXCL12 and binding to CXCR4 $[31,62,63]$. It has been found that the IKK $\alpha$ /noncanonical NF-kB pathway is required for sustained CXCL12/SDF-1 production to induce migration toward HMGB1, indicating that the heterocomplex of HMGB1 and CXCL12/SDF-1 may induce cell migration through the NF-kB pathway [64].

\section{TIM-3}

TIM-3 is a member of the TIM gene family of immunoregulatory proteins. It is composed of an extracellular IgV domain, a mucin-like domain, a transmembrane domain, and an intracellular cytoplasmic tail, which is involved in the recognition of phosphatidylserine (PtdSer) on the surface of apoptotic cells [65]. TIM-3 is associated with the regulation of immune responses in autoimmunity and cancer and is expressed on regulatory $\mathrm{T}$ cells (Treg cells), myeloid cells, natural killer (NK) cells, and mast cells. DC-derived TIM-3 interacts with HMGB1 to suppress the transport of nucleic acids into endosomal vesicles and reduces the therapeutic efficacy of DNA vaccination and chemotherapy by attenuating the immunogenicity of nucleic acids released from dying tumor cells [66]. Anti-TIM-3 monoclonal antibodies can improve the effectiveness of chemotherapy in mice or mice depleted of all DCs [67]. Furthermore, blocking both TIM-3 and programmed cell death 1 (PD1) can improve antitumor $\mathrm{T}$ cell responses in patients with advanced cancers [68]. HMGB1 combined with Tim-3 induces the secretion of angiogenic vascular endothelial growth factor (VEGF) and promotes tumor angiogenesis [69]. The combined induction of antitumor immunity by TIM-3 and HMGB1 has become a potential target for tumor immunogenic chemotherapy and development. 


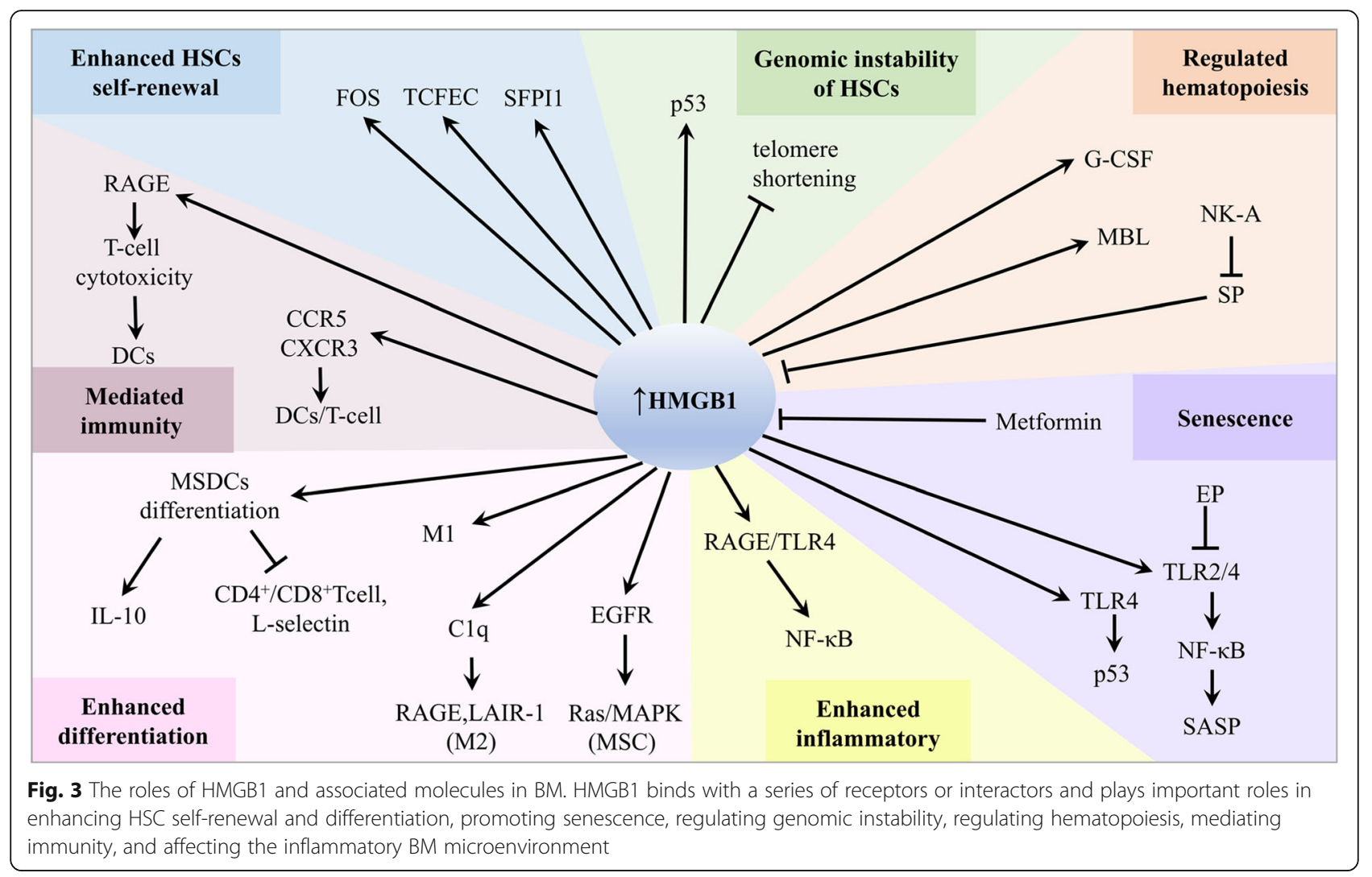

The role of HMGB1 in bone marrow HMGB1 and hematopoietic stem cells

HMGB1 can regulate HSC multipotency and self-renewal at the transcriptional level (Fig. 3). In conjunction with FOS, TCFEC, and SFPI1, HMGB1 confers a clear repopulation advantage to HSCs via a non-cell-autonomous phenomenon [70]. A recent study demonstrated that $\mathrm{HMGB1}^{-/-}$mouse embryonic fibroblasts (MEFs) showed slight telomere shortening but significantly decreased telomerase activity and DNA damage [71]. This indicates that HMGB1 may modulate chromosomal stability of HSCs by altering the functional chromatin structure of telomeres. HMGB1 can also bind to p53 DNA and stimulate DNA linearization, which increases p53 activity [72]. Moreover, the HMGB1 A-box has strong p53 binding activity based on crosslinking chemical and biophysical measurements [73]. HMGB1 regulates not only the transcriptional activity of p53 but also the subcellular localization and phosphorylation of p53.

HMGB1 plays an important role in the mobilization of HSPCs, thus regulating BM microenvironment formation. Altmann $\mathrm{S}$ et al. found that HMGB1 was broadly expressed in canine hematopoietic cells and directly induced the proliferation of peripheral blood mononuclear cells (PBMCs) [74]. Furthermore, mobilization of HSPCs is mainly the result of a sterile inflammatory response to mobilizing stimuli in the BM microenvironment. In the initiation stage of the mobilization process, HMGB1, which binds to mannanbinding lectin (MBL), regulates the mobilization of HSPCs into peripheral blood (PB) [75].

HMGB1 participates in granulocyte colony-stimulating factor (G-CSF)-induced mobilization of HSCs from the $\mathrm{BM}$ into the systemic circulation [76]. Additionally, a clonogenic assay for CFU-granulocyte-monocytes indicated that HMGB1 was required to prevent HSC exhaustion and maintain immune/hematopoietic homeostasis. HMGB1 is linked to substance P (SP) and neurokinin-A (NK-A) to protect the most primitive hematopoietic cells and ensure hematopoietic homeostasis. Mechanistically, HMGB1 negatively regulates hematopoietic stimulation, while SP, a hematopoietic stimulator, decreases HMGB1 expression. Furthermore, NK-A can negatively regulate SP-mediated hematopoietic stimulation [77-79]. The dysfunction of HMGB1 may promote the occurrence and development of hematological malignancies by interfering with the hematopoietic function of the BM.

\section{HMGB1 and the inflammatory bone marrow microenvironment}

The BM is a soft viscous tissue that occupies cavities within the bone [80]. The BM microenvironment is a dynamic network composed of growth factors, cytokines, and stromal cells, which provides a supportive environment for the 
occurrence and development of hematopoietic malignancies [81]. As a cytokine, HMGB1 can bind to RAGE and TLR4 to activate proinflammatory signaling pathways, such as the NF- $\mathrm{kB}$ pathway, and sustain the inflammatory BM microenvironment by inducing cytokine release and recruiting leukocytes. Subsequently, the inflammatory BM microenvironment can accelerate neoplastic transformation and support tumor growth, invasion, and metastases. Infiltrating leukocytes and cancer cells have the ability to secrete HMGB1 in response to hypoxia, injury, inflammatory stimuli, or environmental factors. This loop promotes inflammatory responses and the development of an inflammatory BM microenvironment.

Myeloid-derived suppressor cells (MDSCs) are newly identified immature myeloid cells with immunosuppressive activity. During tumor microenvironment (TME), MDSCs suppress the host anti-tumor immune response through inhibition of $\mathrm{T}$ cell proliferation, cytokine secretion, and recruitment of regulatory $\mathrm{T}$ cells in hematological malignancies. In all hematological malignancies, several strategies to target MDSCs could improve immune therapies via multiple mechanisms, such as hampering MDSCs function, promoting MDSCs maturation, and depleting MDSCs [82-84]. HMGB1 can facilitate MDSCs differentiation in $\mathrm{BM}$ and inhibit the activation of antigen-driven $\mathrm{CD}^{+}$and $\mathrm{CD}^{+}{ }^{+} \mathrm{T}$ cells. HMGB1 also increases MDSCmediated IL-10 production, enhances crosstalk between MDSCs and macrophages, and promotes MDSCs to downregulate the expression of the $\mathrm{T}$ cell-homing receptor L-selectin [85]. Circulating complement C1q can stimulate leukocyte-associated Ig-like receptor-1 (LAIR-1) and maintain monocyte quiescence [86]. Very high levels of HMGB1 induce proinflammatory M1-like macrophage differentiation, and high levels of HMGB1 synergize with C1q via RAGE and LAIR-1 to induce the differentiation of monocytes to anti-inflammatory M2like macrophages [87]. HMGB1 could be released into the BM microenvironment by DCs as a potential immunomodulatory factor to bind with RAGE on the $\mathrm{T}$ cell surface and mediate the interaction between DCs and $\mathrm{T}$ cells, which is involved in the occurrence and development of hematological malignancies [88]. A study also showed that HMGB1 enhances the maturation and accumulation of DCs by promoting CCR5 and CXCR3 production and inducing potent $\mathrm{T}$ cell cytotoxicity [89].

Mesenchymal stem cells (MSCs) play a "double-edged sword" role in hematological malignancies. Studies indicate that MSCs appear to influence pathways that can suppress both proliferation and apoptosis [90]. MSCs protect $\mathrm{T}$ cell acute lymphoblastic leukemia (T-ALL) cells from drug-induced apoptosis though mitochondria transfer mechanism, which eventually leads to chemotherapy resistance [91]. Tumor-associated MSCs are essential components of the TME and also associated with a protumorigenic effect by enhancing tumor cell stemness. HMGB1 also regulates MSCs to promote the inflammatory BM microenvironment formation. HMGB1 acts as a chemoattractant to MSCs. Substantial evidences have revealed that HMGB1 significantly upregulates epidermal growth factor receptor (EGFR) and activates the Ras/ MAPK pathway to regulate the differentiation of MSCs [92]. These results demonstrate that HMGB1 induces MSCs to secrete multiple cytokines, which are predominantly associated with the development of an inflammatory BM microenvironment. Furthermore, HMGB1 in the inflammatory $\mathrm{BM}$ microenvironment can promote the senescence of MSCs via the TLR2/4 and NF- $k B$ signaling pathways, and inhibition of HMGB1 by ethyl pyruvate (EP) can improve lupus nephritis and reverse senescence-associated secretory phenotype (SASP) development [93, 94]. These findings suggest that nuclear HMGB1 can redistribute or relocalize to the extracellular environment in senescent cells. Moreover, senescent fibroblasts secrete oxidized HMGB1, which stimulates cytokine secretion through TLR4 signaling, inducing p53-dependent cellular senescence. Therefore, the alarmin HMGB1 has been considered a central mediator of senescent phenotypes [95]. Interestingly, a recent study found that metformin, a widely used drug for type 2 diabetes, can block HMGB1 translocation and inhibit catabolic production and cell senescence in stem cells (SCs) [96]. Cellular senescence is considered a tumor-suppressive mechanism that permanently arrests cells that are at risk for malignant transformation, can secrete SASP into the BM microenvironment, and transform senescent fibroblasts into proinflammatory cells that have the ability to promote tumor progression $[97,98]$.

\section{The role of HMGB1 in hematopoietic malignancies Myelodysplastic syndromes}

Myelodysplastic syndrome (MDS) is a heterogeneous group of clonal disorders that is characterized by abnormal differentiation of HSCs, ineffective hematopoietic function of $\mathrm{BM}$, and the risk of conversion to acute myeloid leukemia (AML). The inflammatory BM microenvironment is involved in the development and progression of MDS by inducing the apoptotic death of BM progenitor cells. Charoonpatrapong et al. found that DCs released HMGB1 as a potent immunomodulatory cytokine into the BM microenvironment. HMGB1 binds to RAGE on the surface of $T$ cells to mediate the interaction between DCs and T cells [88]. In addition, Velegraki et al. revealed that TLR4 was overexpressed in the BM mononuclear cells of MDS patients compared with those of the control group. TLR4 inhibitors can also inhibit the production of proinflammatory cytokines released by monocytes in patients. Moreover, a study has illustrated that TLR4-dependent inflammatory cytokines not only increase cell apoptosis but also impair the cell 
clearance capacity of macrophages under the influence of the endogenous ligand HMGB1 [52]. Recently, Angel Y.F. and Kam et al. identified HMGB1 as a previously undescribed target that modulated the innate immune system in MDS. This group used combined siRNAs and the small molecule inhibitor sivelestat to study the loss of function of HMGB1 compared to standard chemotherapy. In MDS cells, sivelestat, a neutrophil elastase inhibitor, increases the expression of PUMA and DNA double-strand breaks and activates caspase-3, which indicates that sivelestat can downregulate HMGB1 and suppress the TLR and NF- $\mathrm{kB}$ pathways to promote apoptosis in the BM [99]. The reduction in HMGB1 levels is sufficient to impair MDS cell self-renewal and promote apoptotic cell death. Inhibitors of HMGB1 signaling can provide a first-in-class therapeutic option for patients with MDS and can be used as monotherapy or in combination with chemotherapies to improve the sensitization of MDS cells.

\section{Acute myeloid leukemia}

In acute promyelocytic leukemia (APL), the direct molecular target of all-trans-retinoic acid (ATRA) in human myeloid cells is the PML-RAR $\alpha$ oncoprotein that mediates differentiation [100]. It has been proved that upregulated endogenous HMGB1 promoted autophagy and induced NB4 cell differentiation via ubiquitin-binding adaptor protein p62/SQSTM1-mediated degradation of PML-RAR $\alpha$ oncoprotein [101]. However, long-term exposure of ATRA and arsenic trioxide (ATO) results in hyperinflammation and development of the differentiation syndrome (DS) [102]. HMGB1 promoted ATRA/ATO-induced DS by enhancing inflammation through the MEK/ ERK signaling pathway [103]. Under the induction of specific chemical reagents, murine erythroleukemia (MEL) cells release $\mathrm{HMGBl}$ and promote self-differentiation. However, HMGB1 also mediates the differentiation of MEL cells through pathways other than HMGB1-RAGE [104-107]. During the progression of AML, HMGB1 is secreted to induce TNF- $\alpha$ production and subsequent secretion of IL-1 $\beta$, which stimulates endothelial cells to release stem cell factor (SCF), which can further promote the proliferation of AML cells. HMGB1 is also dependent on the immune receptor Tim-3 to induce angiogenic VEGF secretion and participate in tumor angiogenesis [69]. Additionally, Liu et al. confirmed that miR-34a suppressed the expression of HMGB1 by directly binding with its 3 '-untranslated region (UTR). Overexpression of miR-34a can dramatically reverse apoptosis inhibition by downregulating the expression of HMGB1 in AML [108].

HMGB1 not only is highly expressed and directly induces autophagy in AML cells but also indirectly promotes autophagy to result in therapeutic resistance by enhancing the effect of Beclin-1/PI3KC3 and Atg5-
Atg12-Atg16. Reducing the expression of HMGB1 by miR-34a, miR-181b and miR-142-3p enhances the drug sensitivity of AML cells by inhibiting autophagy; moreover, miR-142-3p directly targets HMGB1 to not only represses autophagy but also reduces P-gp to enhance the drug sensitivity of AML cells [108-110]. HMGB1 also increases the expression of monocyte chemoattractant protein 1 (MCP1) and myeloid cell leukemia 1 (Mcl1) to promote the migration of human leukemia monocytic THP1 cells, which is inhibited by glycyrrhizin (GL) [111]. It has been reported that HMGB1 knockdown reduces the expression of RAGE, which is developed from a cell adhesion molecule family and acts as an adhesion molecule in mammalian cells [112]. Extracellular HMGB1 is not only an important DAMP that is released by cells upon necrosis but also a regulatory factor to prevent AML cell necroptosis. When Z-VAD-fmk inhibits caspase activity, etoposide induces necroptosis by triggering cIAP1/2 depletion [113]. However, extracellular HMGB1 prevents this necroptosis. Interestingly, HMGB1 enhances cell viability and regulates necroptosis through the NF- $\mathrm{kB}$ pathway rather than preventing cIAP1/2 degradation [114].

\section{Chronic myeloid leukemia}

In chronic myeloid leukemia (CML), HMGB1 knockdown can arrest the cell cycle at the G1 phase and inhibit cell proliferation by downregulating the expression of cyclooxygenase-2 (COX-2) [115]. COX-2 activates the Akt/survivin- and Akt/ID3 signaling pathways, which are related to promoting proliferation [116]. Secondgeneration tyrosine kinase inhibitors (TKIs), such as dasatinib, can reactivate the induction of apoptotic cell death in patients with imatinib-refractory CML and Philadelphia chromosome-positive ALL $\left(\mathrm{Ph}^{+} \mathrm{ALL}\right)$. However, HMGB1-mediated necroptosis gives rise to dasatinib-induced cardiotoxicity, which reduces the clinical applications of dasatinib, indicating that targeting HMGB1 may be a viable strategy to prevent dasatinibinduced cardiotoxicity [117]. A tetrahydrobenzimidazole derivative TMQ0153 has a strong pro-oxidant effect against imatinib-sensitive and imatinib-resistant CML cells. TMQ0153 treatment significantly stimulates the release of HMGB1, leading to immunogenic cell death (ICD), which is a form of chemotherapy-induced tumor cell death [118]. Yang et al. found that cytoplasmic HMGB1 reduced the sensitivity of CML cells to death induced by anticancer drugs by upregulating the autophagy pathway. HMGB1 overexpression increases the transcriptional activity of JNK, ERK, and Beclin-1 [119]. Chen et al. found that HMGB1 knockdown promoted the apoptosis of $\mathrm{K} 562$ cells by increasing Bax protein and reducing Bcl-2 protein [115]. Conversely, HMGB1 overexpression inhibits ADM-induced apoptosis in K562 
cells by regulating $\mathrm{Bcl}-2$ protein levels and the activity of caspase-3/9 [120]. Moreover, knockdown of HMGB1 significantly inhibits the adhesion of K562 cells [115].

\section{Acute lymphocytic leukemia}

Vincristine, corticosteroids, and L-asparaginase in conjunction with intrathecal therapy can completely alleviate $95 \%$ of ALL in patients [121]. Compared with the healthy control and ALL patients with complete remission, serum HMGB1 level of ALL patients was increased, but there was no significant difference in HMGB1 level between the healthy control group and ALL complete remission group, indicating that serum HMGB1 is a useful biomarker to evaluate the prognosis of childhood ALL. Moreover, HMGB1 may be associated with the stages of hemocyte differentiation and maturation. HMGB1 is released from ALL cells and promotes inflammation by stimulating leukemic cells to secrete TNF- $\alpha$ through a MAPK-dependent mechanism [122]. This finding indicates that HMGB1 expression is positively correlated with the clinical status of ALL patients. Moreover, the Ulk1-Atg13-FIP200 complex, which is upstream of HMGB1-Beclin1 and PI3KC3-Beclin1 complexes, promotes HMGB1 trafficking and consequently upregulates autophagy. Therefore, targeting the transformation of autophagic complexes or HMGB1 translocation may inhibit autophagy, and thus reverse ALL drug resistance [123]. Unlike common miRNA effects with negative correlations, inhibition of miR-181a expression induces a decrease in HMGB1 protein in T-and B-ALL cells. This suggests that dysregulation of HMGB1, perhaps due to miR-181a dysregulation, promotes leukemogenesis [124]. Anthracycline can induce a tumorspecific immune response through HMGB1 release in the late stage, and play a role in enhancing the antigen expression of dead tumor cells to DCs through the TLR4 receptor in ALL cells [125].

\section{Lymphoma}

The expression level of HMGB1 in many primary lymphomas is higher than the average level in normal lymph nodes, and HMGB1 is only detected in lymphoma cells. There is a correlation between HMGB1 expression and classification [126]. Chronic lymphocytic leukemia (CLL) is the most common subtype of non-Hodgkin lymphoma (NHL) and is mainly characterized by mature small lymphocytes invading $\mathrm{PB}$ and lymphoid tissues such as BM, lymph nodes, and the spleen. Jia et al. found that the plasma HMGB1 levels in CLL patients were significantly higher than those of the healthy control group, and the HMGB1 concentration was related to the absolute lymphocyte count. Furthermore, CLL cells passively release HMGB1 through the HMGB1-RAGE/TLR9 pathway and differentiate $\mathrm{CD} 14^{+}$monocytes from CLL cells into nurse-like cells (NLCs), thus regulating the microenvironment. The high number of NLCs is related to the short survival time of CLL patients [127]. Cutaneous $\mathrm{T}$ cell lymphoma (CTCL), the second most common extranodal NHL, is characterized by clonal accumulation of postthymic $\mathrm{T}$ cells residing in the skin and represents a group of diseases such as mycosis fungoides (MF) and Sézary syndrome (SS) [128, 129]. Senda et al. demonstrated that HMGB1 expression in sera is increased in CTCL patients and correlates with serum levels of soluble IL-2 receptor, lactate dehydrogenase, thymus and activation-regulated chemokines, and the number of eosinophils in $\mathrm{PB}$. It was also found that the level of HMGB1 mRNA in CTCL-injured skin was significantly increased and positively correlated with $I L-4, I L-10, I L$ 19, and angiogenin mRNA levels [130]. It has been reported that IL-4, IL-10, and IL-19 are associated with Th2 polarization [131-133]. These results suggest that enhanced HMGB1 expression may contribute to the progression of CTCL through Th2 polarization and promotion of angiogenesis [130]. Notably, Fredholm S. et al. proved that $72 \%$ of CTCL patients had pY-STAT3positive malignant $\mathrm{T}$ cells, and staining for eosinophils and the trafficking factor HMGB1 was also positive, which supports HMGB1 as a possible therapeutic target [134].

To evaluate the significance of HMGB1 in patients with $\mathrm{T}$ cell lymphoma, a study found that the expression of HMGB1 in 120 cases of T cell lymphoma was significantly higher than that in 40 cases of reactive lymphoid hyperplasia. Furthermore, the positivity rate of HMGB1 was used as an indicator for diagnosing $\mathrm{T}$ cell lymphoma in patients with lymph node biopsy. The specificity of this finding was $63.7 \%$, which was significantly associated with malignancy and clinical stage but not gender, age, or tumor location. Elevated expression of HMGB1 may be a potential diagnostic marker for the development and progression of $\mathrm{T}$ cell lymphoma [135]. Zhao $\mathrm{T}$ et al. demonstrated that rituximab-induced inhibition of STAT3 activity led to an increase in HMGB1 release and a decrease in IL-10 secretion, triggering immune responses and greatly improving the clinical outcome of patients with diffuse large B cell lymphoma (DLBCL), suggesting that indirectly affecting the immune system rather than directly killing cells led to the elimination of DLBCL [136]. Conversely, HMGB1 stimulates DLBCL cell proliferation by activating the Src/ERK pathway, which is inhibited by EP, causing an accumulation of p27 and cell cycle arrest in the G1 to $S$ phase transition. It has been suggested that EP-mediated blockade of the HMGB1-mediated signaling pathway can effectively inhibit the occurrence of DLBCL and disease progression [137]. Moreover, in their studies, HMGB1 plays a dual role in DLBCL as an inflammatory factor that promotes tumorigenesis and as a cytokine that induces immune 
responses, which further indicates that HMGB1 has a potential application in the pathogenesis and treatment of DLBCL [138].

In anaplastic large-cell lymphomas (ALCLs), Dejean et al. found that HMGB1 could activate the MMP-9, PAR-2, and NF- $\mathrm{KB}$ pathways to induce the release of IL8, which bound to CXCR1 and CXCR2 on the surface of ALK-positive lymphoid cells to promote the proliferation and metastasis of lymphoid cells. After treatment with the HMGB1 inhibitor glycyrrhiza, the invasion and metastatic abilities of lymphoma cells were significantly decreased [139]. Adult T cell leukemia (ATL) patients have high plasma HMGB1 levels compared with normal controls [140]. It has been reported that high plasma HMGB1 levels in patients with ATL are caused by infection with human $\mathrm{T}$ cell lymphotropic virus type $\mathrm{I}$ (HTLV-I) [141]. In addition, HMGB1 mRNA is abundantly expressed in HTLV-I-infected T cell lines. The HTLV-I oncoprotein Tax enhances the expression of the $H M G B 1$ gene at the transcriptional level by interacting with $\mathrm{C} / \mathrm{EBP}$ and inducing extracellular release of HMGB1 by $T$ cells. These results suggest that HMGB1 is a potential biomarker and a therapeutic target for ATL [140, 142].

\section{Multiple myeloma}

In MM, high expression of HMGB1 is negatively associated with the 3-year survival of MM patients, which may be involved in promoting MM drug resistance. HMGB1 could participate in DNA damage repair and autophagy. In contrast, when HMGB1 is downregulated, the sensitivity of MM cells to dexamethasone (Dex) is enhanced by activating the mTOR pathway to inhibit autophagy and induce apoptosis [143]. Similarly, Gao et al. found that the expression of the lncRNA MALAT-1 and HMGB1 was dramatically increased in patients with untreated MM, while MALAT-1 expression and HMGB1 protein levels in patients with complete remission were significantly decreased. Furthermore, MALAT-1 increases the expression of HMGB1 at the posttranslational level by inducing HMGB1 ubiquitination in MM cells, thereby promoting autophagy and inhibiting apoptosis [29]. In addition, Roy M. et al. revealed that the expression of HMGB1 increased in MM bortezomibresistant cells, and bortezomib combined with lycorine efficiently resensitized resistant cells to bortezomib. Mechanistically, the proteasomal degradation of the HMGB1 by lycorine inactivates the MEK-ERK pathway, inhibiting Bcl-2 dissociation from Beclin-1 and consequently suppressing autophagy [30]. Therefore, HMGB1 is an important target for MM patients to increase chemotherapy drug sensitivity.

Interestingly, HMGB1 can also participate in other pathological processes in MM. Similar to DAMPs emitted by apoptotic MM cells, HMGB1 fosters an immunogenic microenvironment to promote antitumor immunity. Recently, studies showed that chemotherapeutic agents, such as melphalan and docosahexaenoic acid (DHA), promoted the release of HMGB1 by ICD, leading to an immune response [144, 145]. Moreover, HMGB1 can act as a thrombosis-related biomarker in patients with MM. After Mel-P, bortezomib, and lenalidomide therapies, the plasma concentrations of HMGB1 were reduced in association with the risk of thrombosis [146, 147]. CXCR4 plays an important role in proliferation, invasion, dissemination, and drug resistance in MM [148]. This indicates that its ligand HMGB1 could regulate MM physiological processes. Because of its pivotal role in the progression of $M M$, HMGB1 is considered one of the most important potential targets for inhibiting tumor growth, metastasis, and drug resistance and optimizing current anti-MM treatment strategies (Table 1).

\section{The potential clinical applications of HMGB1 Hematopoietic stem cell transplantation}

Hematopoietic stem cell transplantation (HSCT) is an intensive therapy to treat hematologic malignancies, but graft-versus-host disease (GVHD) is a frequent severe inflammatory complication that is associated with poor outcomes [149]. Yujiri et al. found increased serum levels of HMGB1 in patients who developed acute GVHD (aGVHD) after HSCT, which indicates that HMGB1 may be a useful indicator of GVHD [150]. Additionally, enhanced HMGB1 is reported to promote STAT3 expression in $\mathrm{CD}^{+} \mathrm{T}$ cells via modulation of its DNA methylation, subsequently inhibiting Tregs and promoting the Th17 response during GVHD [151]. It has been demonstrated that genetic variations in cytokine genes can modulate immune reactions after HSCT. An inherited variation in HMGB1 is associated with outcomes after allogeneic HSCT (allo-HSCT) [152]. Thus, HMGB1 is likely to play an important role in the development of GVHD, known as the graft-versus-tumor (GVT) effect, and possibly engraftment because of its central role in the activation of APCs and tissue regeneration. Moreover, the compound cyclopentylamino carboxymethylthiazolylindole (NecroX)-7 could protect mice against lethal GVHD by reciprocal regulation of regulatory $\mathrm{T} / \mathrm{Th} 1$ cells, attenuating systemic HMGB1 accumulation and inhibiting the HMGB1-mediated inflammatory response [153]. Cyclophosphamide (CY) in combination with either ablative doses of total body irradiation (TBI) or the oral alkylating agent busulfan $(\mathrm{Bu})$ is the most common conditioning regimen for allo-HSCT. However, TBI and CY can mobilize HMGB1 to the PB, and increased levels of HMGB1 correlate with increased PAI-1 after alloHSCT, inducing transplantation-associated coagulopathy 
Table 1 Cellular functions of HMGB1 and related interactors in various types of hematopoietic malignancies

\begin{tabular}{|c|c|c|c|c|c|}
\hline Tumor & Sources of HMGB1 & Cellular function & Interactors and pathways & Inhibitors & References \\
\hline \multirow[t]{3}{*}{ MDS } & DCs & Interacts with $\mathrm{T}$ cells to mediate DCs & RAGE & NR & {$[88]$} \\
\hline & Plasma and BM & $\begin{array}{l}\text { Impairs the ability of macrophages to } \\
\text { phagocytose apoptotic cells }\end{array}$ & TLR4 & TLR4 inhibitors & {$[52]$} \\
\hline & BM & $\begin{array}{l}\text { Modulates the innate immune system } \\
\text { and inhibits apoptosis }\end{array}$ & TLRs and NF-KB pathways & $\begin{array}{l}\text { HMGB1 siRNAs and } \\
\text { sivelestat }\end{array}$ & [99] \\
\hline \multirow[t]{8}{*}{ AML } & APL cell line NB4 & $\begin{array}{l}\text { Mediates autophagy and affects the } \\
\text { degradation of PML-RARa }\end{array}$ & ROS, p62/SQSTM and PML-RARa & NAC & [101] \\
\hline & APL & $\begin{array}{l}\text { Enhances inflammation and promotes } \\
\text { ATRA/ATO-induced DS }\end{array}$ & MEK/ERK pathways & NR & [103] \\
\hline & MEL cells & Promotes MEL cells differentiation & NR & NR & {$[106]$} \\
\hline & NR & $\begin{array}{l}\text { Stimulates AML cells proliferation and } \\
\text { angiogenesis }\end{array}$ & TNF- $a$ and Tim-3 & NR & {$[69]$} \\
\hline & AML cells & $\begin{array}{l}\text { Represses apoptosis and promotes } \\
\text { autophagy and therapeutic resistance }\end{array}$ & Beclin-1/PI3KC3, Atg5-Atg12-Atg16 & $\begin{array}{l}\text { MiR-34a, MiR-181b3, MiR- } \\
\text { 142-3p }\end{array}$ & [108-110] \\
\hline & THP cells & Promotes migration & MCP-1 and Mcl-1 & $\mathrm{GL}$ & [111] \\
\hline & Mammalian cells & Reduces adhesion & RAGE & NR & [112] \\
\hline & Extracellular & Prevents necroptosis & NF-kB pathway & NR & {$[114]$} \\
\hline \multirow[t]{3}{*}{ MPN } & CML cells & Promotes proliferation & $\begin{array}{l}\text { COX-2, Akt/surviving and Akt/ID3 } \\
\text { pathways }\end{array}$ & Cordycepin & [115] \\
\hline & Cytoplasmic & $\begin{array}{l}\text { Decreases CML cells sensitivity to } \\
\text { anticancer drugs }\end{array}$ & JNK, ERK and Beclin-1 & NR & [119] \\
\hline & CML cells & Inhibits apoptosis & Bax, BCl-2 and ROS & HMGB1 knockdown & {$[115]$} \\
\hline \multirow[t]{4}{*}{ ALL } & ALL cells & Promotes inflammation & TNF- $a$ and MAPK & NR & {$[122]$} \\
\hline & & $\begin{array}{l}\text { Upregulates autophagy and } \\
\text { chemoresistance }\end{array}$ & $\begin{array}{l}\text { Ulk1-Atg13-FIP200 complex and } \\
\text { Beclin1 }\end{array}$ & NR & [123] \\
\hline & T- and B-ALL cells & NR & NR & MiR-181a & {$[124]$} \\
\hline & Pyroptosis cells & Induces cytokine release and CRS & IL-6 and GSDME & NR & {$[125]$} \\
\hline CLL & CLL cells & Differentiates monocytes into NLCs & RAGE/TLR9 & NR & {$[127]$} \\
\hline \multirow[t]{2}{*}{ CTCL } & Peripheral blood & $\begin{array}{l}\text { Promotes Th2 polarization and } \\
\text { angiogenesis }\end{array}$ & IL-4, IL-10, IL-19 and angiogenin & NR & [130] \\
\hline & Extracellular & Stimulates DLBCL cell proliferation & Src/ERK pathway & EP & [137] \\
\hline ALCLs & Extracellular & $\begin{array}{l}\text { Promotes the proliferation and } \\
\text { metastasis of lymphoid cells. }\end{array}$ & NR & GL & [139] \\
\hline \multirow[t]{5}{*}{ MM } & Extracellular & $\begin{array}{l}\text { Promotes drug resistance, DNA } \\
\text { damage repair and autophagy }\end{array}$ & NR & NR & {$[143]$} \\
\hline & Nucleus and cytosol & $\begin{array}{l}\text { Promotes autophagy and inhibits } \\
\text { apoptosis }\end{array}$ & ubiquitination & LncRNA MALAT-1 & [29] \\
\hline & $\begin{array}{l}\text { MM bortezomib- } \\
\text { resistant cells }\end{array}$ & $\begin{array}{l}\text { Degrades HMGB1 protein and } \\
\text { inhibits autophagy }\end{array}$ & MEKJERK pathway & Lycorine & {$[30]$} \\
\hline & Apoptotic MM cells & $\begin{array}{l}\text { Fosters an immunogenic } \\
\text { microenvironment and promotes } \\
\text { antitumor immunity }\end{array}$ & NR & NR & {$[144,145]$} \\
\hline & Extracellular & $\begin{array}{l}\text { Acts as a thrombosis-related } \\
\text { biomarker }\end{array}$ & NR & NR & {$[146,147]$} \\
\hline
\end{tabular}

NR not reported, MPN myeloproliferative neoplasms

(TAC) conditions such as veno-occlusive disease (VOD) [154]. Recombinant human soluble thrombomodulin (rhTM) is used to treat disseminated intravascular coagulation (DIC) caused by aGVHD and significantly decreases HMGB1 [155]. Extracorporeal photopheresis (ECP) depends on infusion of UVA-irradiated and 8 methoxy- psoralen (PUVA)-treated leukocytes and is an effective treatment measure for GVHD. In vitro PUVA treatment induces the expression of HMGB1 in dying T cells, especially upon $\mathrm{T}$ cell activation, leading to their phagocytosis by macrophages and DCs [156]. In AML patients who received allo-HSCT, a higher $\gamma \delta \mathrm{T}$ cell count, which is an 
important early source of TNF- $\alpha$ and IFN- $\gamma$, predicted a better prognosis. A recent study found that PD- $1^{+} \mathrm{TIM}-3^{+}$ V82 T cells, PD-L1, and HMGB1 were significantly higher in AML patients than in healthy controls, suggesting that PD-1 alone is insufficient to indicate functional impairment, and V82 $\mathrm{T}$ cells may require anti-TIM-3 inhibition for functional revival [157].

\section{HMGB1 and chemoresistance in hematopoietic malignancies}

Acquired chemoresistance is a major obstacle in the clinical treatment of hematological malignancies. Many studies have demonstrated that chemotherapy agents including docetaxel, doxorubicin (DNR), cisplatin, etoposide, and methotrexate induce HMGB1 upregulation and promote cytosolic HMGB1 translocation [158-160]. Moreover, DNR, vincristine (VCR), etoposide (VP-16), cytosine arabinoside (Ara$\mathrm{C})$, adriamycin (ADM), and ATO can increase HMGB1 expression and promote chemoresistance in hematological malignancies [22, 44]. Downregulating HMGB1 inhibits autophagy and enhances bortezomib activity in MM [30]. HMGB1 is becoming a recognized therapeutic target for chemotherapy resistance (Fig. 4) [161].

\section{Autophagy}

Autophagy is a degradation mechanism that alters cells to restore their energy balance during periods of varying nutrient availability [162]. However, autophagy improves the survival of cancer cells at the later times under stressful conditions, such as nutrient depletion, hypoxia, and therapeutic damage [163]. Blocking autophagy could increase cancer cells sensitivity to chemotherapy. For instance, bortezomib-induced MCL cell death was significantly potentiated by compounds that interfered with autophagosomal function [164]. HMGB1-dependent autophagy promotes chemotherapy resistance in three ways: nuclear HMGB1 upregulates the expression of HSP27, cytoplasmic HMGB1 activates the Beclin-1/PI3K-III complex, and extracellular HMGB1 binds to RAGE $[45,165]$. By targeting HMGB1, autophagy inhibition is a potential therapeutic strategy for hematopoietic malignancies [166, 167]. Nuclear HMGB1 can activate the HSP27 pathway during autophagy, and the Pink1/Parkin pathway is required for HMGB1/HSP27-dependent mitophagy. The HSP27 pathway may be a potential mechanism by which HMGB1

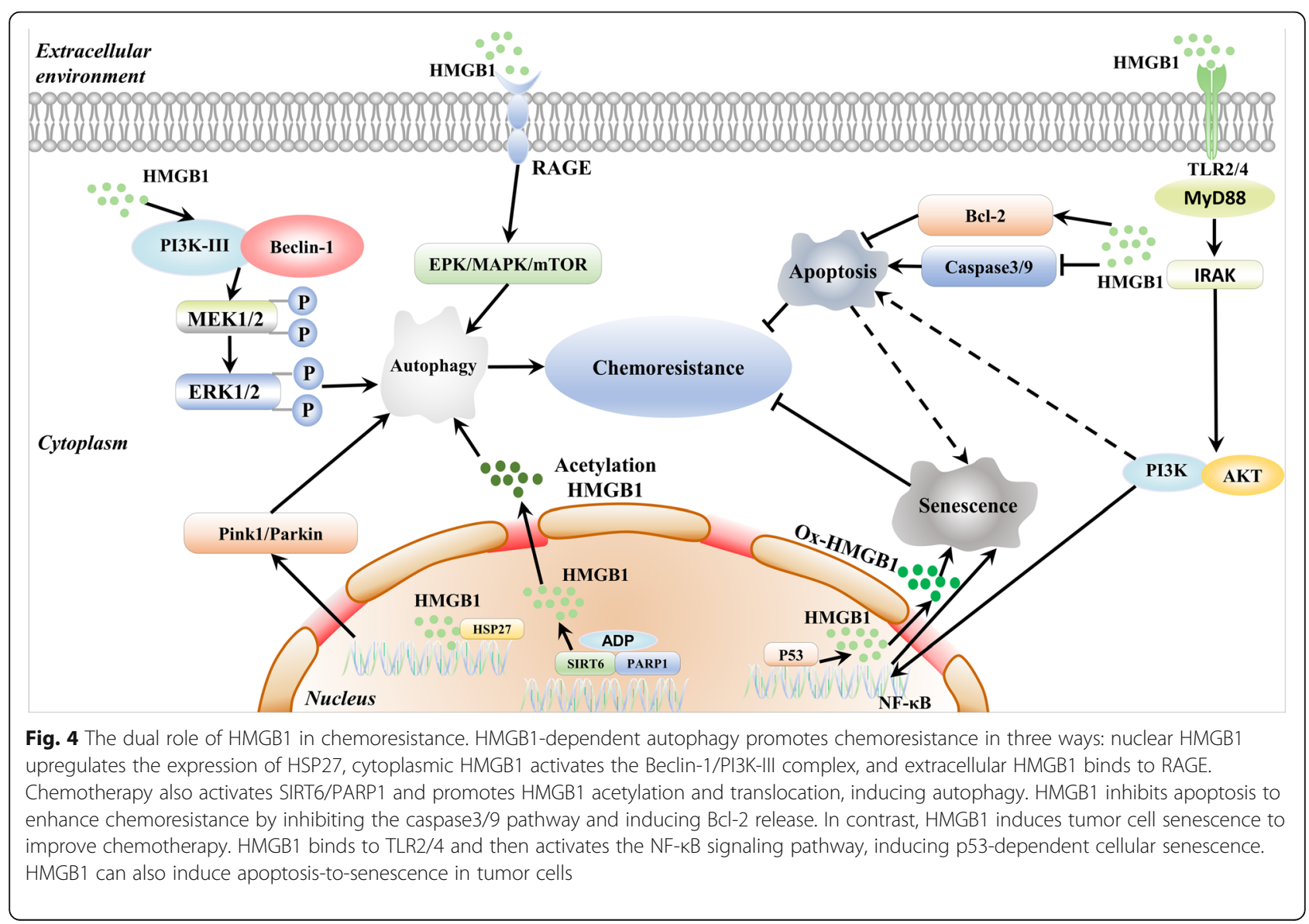


regulates nuclear autophagy $[168,169]$. In autophagyrelated chemoresistance, the dissociation and recoupling of autophagic complexes are essential events. HMGB1 gene transfection can increase the LC3-II level and inhibit the rapamycin complex 1 (mTORC1) pathway to strongly induce autophagy and promote chemoresistance in leukemia cells [170, 171]. HMGB1 is released from dying cancer cells and enhances autophagy-induced chemoresistance and regrowth via RAGE-mediated ERK/Drp1 phosphorylation. HMGB1 and RAGE inhibitors abolish Drp1 phosphorylation and significantly enhance sensitivity to chemotherapeutic treatment by suppressing autophagy [172]. Moreover, treating leukemic cells with chemotherapeutic drugs leads to the translocation of HMGB1, which is involved in autophagy and ultimately promotes chemoresistance in leukemia. Chemotherapy-induced ADPribosylation activates SIRT6 and PARP1 and then promotes HMGB1 acetylation and translocation, finally resulting in chemotherapy-induced autophagy in leukemic cells $[22,24]$.

\section{Apoptosis inhibition}

Apoptosis generally occurs through two different pathways: the internal pathway and the external pathway. HMGB1 inhibits both apoptosis pathways, thereby enhancing chemoresistance in cancer cells. HMGB1 can inhibit the caspase $3 / 9$ pathways, releasing proapoptotic initiators (Bax-Bak) and inducing the expression of antiapoptotic proteins (Bcl-2) [173]. For example, HMGB1 inhibits apoptosis in leukemia K562 cells by regulating the protein level of $\mathrm{Bcl}-2$ and the activity of caspase- 3 and caspase-9 [120]. It was also found that inhibition of HMGB1 with siRNAs and sivelestat could activate caspase-3 and promote MDS cell death [99].

\section{Senescence}

HMGB1 binds to TLR2/4 and then activates the NF- $\mathrm{kB}$ signaling pathway to induce p53-dependent cellular senescence $[94,95]$. Interestingly, the HMGB1 protein is a double-edged sword. As an antiapoptotic protein, HMGB1 promotes chemotherapy resistance. However, as an enhancer of senescence, HMGB1 induces tumor cells to undergo an apoptosis-to-senescence shift to improve chemotherapy effectiveness [174]. This suggests that HMGB1 could be a target for selectively enforcing tumor suppression. These findings provide new insights into the mechanism of resistance to chemotherapy drugs.

\section{The therapeutic strategies to inhibit HMGB1 in cancer}

To date, several strategies have been proposed to directly or indirectly inhibit HMGB1 expression, release, and activity to treat hematopoietic malignancies (Table 2).

\section{Anti-HMGB1 antibodies}

Administration of a polyclonal HMGB1-neutralizing antibody inhibited HMGB1-induced autophagy and increased the sensitivity of leukemia cells to chemotherapy, suggesting that HMGB1 is a potential drug target for therapeutic interventions [175]. Several anti-HMGB1 monoclonal antibodies have been developed for clinical applications. The monoclonal antibody 2G7 binds to the HMGB1 epitope containing aa 53-63 and has shown beneficial therapeutic effects in experimental models of arthritis, lupus nephritis (LN) and drug-induced liver injury [176-178].

\section{Targeting receptors}

Soluble RAGE (s-RAGE) is an endogenous cleaved soluble form of RAGE that blocks the HMGB1-RAGE signaling pathway in animal tumor models and has decoy receptor properties [179]. Recombinant HMGB1 A-box efficiently interacts with RAGE, competing with the HMGB1 protein to bind to RAGE, and this peptide lacks the proinflammatory cytokine activity of the B-box [5]. TAT-labeled HMGB1 A-box-His6 (TAT-HMGB1A) was used as a pharmaceutical protein ex vivo and significantly reduced the secretion of endogenous HMGB1 protein by structurally modulating its cellular membrane penetration [180].

\section{Small molecules}

GL, a triterpenoid saponin glycoside of glycyrrhizic acid, specifically binds to both HMG boxes of the HMGB1 cytokine, inhibiting HMGB1-induced proliferation and migration, as well as the formation of blood vessels, and reducing HMGB1-stimulated inflammatory conditions [181]. GL also suppresses HMGB1 phosphorylation and secretion by reducing the interaction between HMGB1 and protein kinase $\mathrm{C}$ (PKC) or calcium/calmodulin-dependent protein kinase IV (CaMKIV) [182]. EP, an anti-inflammatory factor, directly chelates calcium and inhibits HMGB1 phosphorylation and secretion [183]. EP also attenuates the active secretion of HMGB1 by inducing heme oxygenase-1 (HO1) expression via activation of the PI3K/Akt and Nrf2 pathways [184]. Moreover, EP reverses the HMGB1-induced senescent phenotype of BM-MSCs and prolongs the survival of MRL/lpr mice [93]. EP also impairs HMGB1 secretion, leading to reduced RAGE expression and NF-kB/ STAT3 pathway activation [185]. As an antioxidant, quercetin promotes apoptosis by attenuating the expression of HMGB1 and RAGE and suppressing the activation of NF$\kappa B$ in MCF-7 cells [186]. A novel type of HMGB1 secretion inhibitor, erythropoietin (inflachromene, ICM), increases the ubiquitination of Beclin-1 by enhancing the interaction between Beclin-1 and the E3 ubiquitin ligase RNF216, inhibiting HMGB1 nucleoplasmic translocation and thereby inhibiting autophagy [187]. Stearoyl lysophosphatidylcholine (sLPC), a traditional Chinese medicine ingredient, 
Table 2 The effects of various HMGB1 inhibitors

\begin{tabular}{|c|c|c|c|}
\hline Compound & $\begin{array}{l}\text { Type of } \\
\text { studies }\end{array}$ & Biological function & References \\
\hline $\begin{array}{l}\text { HMGB1-neutralizing } \\
\text { antibody }\end{array}$ & In vitro & Inhibits HMGB1-induced autophagy and increases the sensitivity of leukemia cells to chemotherapy & [175] \\
\hline $\mathrm{mAb}(2 \mathrm{G} 7)$ & In vivo & Improves arthritis, LN and drug-induced liver injury & {$[176-178]$} \\
\hline s-RAGE & In vivo & Blocks the HMGB1-RAGE signaling pathway & [179] \\
\hline HMGB1 A-box & In vitro & Inhibits the proinflammatory actions of the B-box & {$[5]$} \\
\hline TAT-HMGB1A & In vitro & Reduces secretion of endogenous HMGB1 protein & [180] \\
\hline $\mathrm{GL}$ & $\begin{array}{l}\text { In vitro, in } \\
\text { vivo }\end{array}$ & Suppresses HMGB1 phosphorylation and secretion via PKC/CaMKIV & [181] \\
\hline EP & $\begin{array}{l}\text { In vitro, in } \\
\text { vivo }\end{array}$ & $\begin{array}{l}\text { Inhibits HMGB1 secretion by inducing HO-1 via PI3K/Akt and Nrf2 pathways; reverses the HMGB1- } \\
\text { induced senescent phenotype of BM-MSCs; reduces RAGE expression and NF-KB/STAT3 pathway } \\
\text { activation }\end{array}$ & $\begin{array}{l}{[93,184,} \\
185]\end{array}$ \\
\hline quercetin & In vitro & $\begin{array}{l}\text { Promotes apoptosis by attenuating the expression of HMGB1 and RAGE and suppressing the } \\
\text { activation of NF-KB }\end{array}$ & [186] \\
\hline ICM & In vitro & $\begin{array}{l}\text { Inhibits HMGB1 nucleoplasmic translocation and autophagy by enhancing the interaction between } \\
\text { Beclin-1 and E3 ubiquitin ligase RNF216 }\end{array}$ & [187] \\
\hline SLPC & In vivo & Suppresses HMGB1 phosphorylation and extracellular release & [188] \\
\hline P5779 & $\begin{array}{l}\text { In vitro, in } \\
\text { vivo }\end{array}$ & Interrupts disulfide-HMGB1/MD-2 binding; suppresses HMGB1-induced TNF release & [189] \\
\hline rTM & $\begin{array}{l}\text { In vitro, in } \\
\text { vivo }\end{array}$ & $\begin{array}{l}\text { Decreases serum HMGB1 levels and improves SIRS in hematological malignancies; improves DIC in } \\
\text { AML; inhibits HMGB1 protein secretion and inhibits I-KB phosphorylation }\end{array}$ & [190-192] \\
\hline
\end{tabular}

suppresses HMGB1 phosphorylation and inhibits LPSinduced extracellular release of HMGB1 through the G2A/ calcium/CaMKK $\beta / A M P K$ pathway [188].

\section{Small peptides and peptidomimetics}

A peptide inhibitor of HMGB1 (P5779) that selectively interrupts disulfide-HMGB1/MD-2 binding without inhibiting other TLR4/MD-2 ligands has been identified [35]. Recently, it was demonstrated that folic acid mimics the binding of P5779 at the intersection of TLR4 and MD-2. These folic acid-derived P5779 mimetics inhibit HMGB1-induced TNF release in human macrophages [189]. Recombinant human thrombomodulin (rTM) significantly decreases serum HMGB1 levels and improves systemic inflammatory response syndrome (SIRS) in patients with hematological malignancies [190]. In AML patients, rTM can successfully treat DIC, which is correlated with platelet-derived HMGB1 [191, 192]. Moreover, rTM administration inhibits HMGB1 protein secretion and the activation of NF- $\mathrm{kB}$ by inhibiting I-kB phosphorylation [193, 194].

\section{Conclusions and perspectives}

HMGB1 has been confirmed to exert various effects on pathological symptoms and different stages of hematological malignancies. HMGB1 may be a very useful biomarker for the diagnosis and prognosis of hematological malignancies. Moreover, HMGB1 is related to the chemoresistance of various hematological malignancies. To date, the PTM of HMGB1 in the context of various hematological malignancies remains mostly unexplored; likewise, the redox forms of HMGB1 that are involved in hematological malignancies have not been revealed in detail. This has opened up promising new avenues of investigation in these fields.

Although HMGB1 has an important impact on hematopoietic regulation of HSCs and the inflammatory $\mathrm{BM}$ microenvironment, it is not clear how HMGB1 is involved in the development of HSCs into hematological malignancies. Furthermore, HMGB1 is released into the extracellular environment from activated immune cells or passively released from damaged or necrotic cells. Extracellular HMGB1 is a risk factor for a series of hematological malignancies. Likewise, HMGB1 is not only an antiapoptotic protein but also an enhancer of senescence, and plays a dual role in the regulation of drug resistance in leukemia cells. The application of targeting antibodies or biological inhibitors of HMGB1 as therapeutic drugs is still confronted with a variety of challenges.

In conclusion, it is necessary to further understand the mechanism by which extracellular and nuclear HMGB1 affects HSCs and the BM microenvironment and how to maximize its therapeutic potential in different hematological malignancies.

\section{Abbreviations}

ADM: Adriamycin; aGVHD: Acute GVHD; ALCLs: Anaplastic large-cell lymphomas; allo-HSCT: Allogeneic HSCT; AML: Acute myeloid leukemia; AraC: Cytosine arabinoside; ATO: Arsenic trioxide; ATRA: All-trans-retinoic acid; AP1: Activator protein 1; APL: Acute promyelocytic leukemia; ATL: Adult T cell 
leukemia; BM: Bone marrow; Bu: Busulfan; CaMKIV: Calcium/calmodulindependent protein kinase IV; CBP: CREB-binding protein; CLL: Chronic lymphocytic leukemia; CML: Chronic myeloid leukemia; COX2: Cyclooxygenase-2; CRM-1: Chromosome-region maintenance-1; CTCL: Cutaneous T cell lymphoma; CXCL: CXC motif ligand 12; CXCR4: CXC motif chemokine receptor type 4; CY: Cyclophosphamide; DAMPs: Damageassociated molecular pattern molecules; DCs: Dendritic cells; Dex: Dexamethasone; DIC: Disseminated intravascular coagulation; DLBCL: Diffuse large B cell lymphoma; DNR: Doxorubicin; dsHMGB1: Disulfide HMGB1; ECP: Extracorporeal photopheresis; EGFR: Epidermal growth factor receptor; EP: Ethyl pyruvate; ERK1/ 2: Extracellular signal-regulated kinase 1 and 2 (ERK1/2); fr-HMGB1: Fully reduced HMGB1; G-CSF: Granulocyte colony-stimulating factor; GL: Glycyrrhizin; GPCR: G-protein-coupled seven-transmembrane receptor; GVHD: Graft-versus-host disease; GVT: Graft-versus-tumor; HMG: High mobility group protein; HMGB1: High-mobility group box 1; HO-1: Heme oxygenase1; HSCs: Hematopoietic stem cells; HSCT: Hematopoietic stem cell transplantation; HTLV-I: Human T cell lymphotropic virus type I; ICD: Immunogenic cell death; ICM: Inflachromene; IFN: Interferon; IgV: Immunoglobulin variable; IL-6: Interleukin-6; LAIR-1: Leukocyte-associated Ig-like receptor-1; LN: Lupus nephritis; LRRs: Leucine-rich repeats; MAPK: Mitogen-activated protein kinase; MBL: Mannan-binding lectin; Mcl1: Myeloid cell leukemia 1; MCP1: Monocyte chemoattractant protein 1; MDS: Myelodysplastic syndrome; MDSC: Myeloid-derived suppressor cell; MEFs: Mouse embryonic fibroblasts; MEL: Murine erythroleukemia; MF: Mycosis fungoides; MM: Multiple myeloma; M-MDSC: Monocytic-MDSC; MSCs: Mesenchymal stromal cells; mTOR: Rapamycin; mTORC1: Rapamycin complex 1; NecroX: Cyclopentylamino carboxymethylthiazolylindole; NESs: Nuclear export signals; NHL: Non-Hodgkin lymphoma; NK cells: Natural killer cells; NK-A: Neurokinin-A; NLCs: Nurse-like cells; NLSs: Nuclear localization sequences; OA: Okadaic acid; ox-HMGB1: Oxidized HMGB1; p300: Histone acetyltransferase p300; PB: Peripheral blood; PBMCs: Peripheral blood mononuclear cells; PCAF: P300/CBP-associated factor;

PD1: Programmed cell death 1; $\mathrm{Ph}^{+}$ALL: Philadelphia chromosome-positive acute lymphoblastic leukemia; PKC: Protein kinase C; PPAR-Y: Peroxisome proliferator-activated receptor gamma; PRRs: Pattern recognition receptors; PtdSer: Phosphatidylserine; PTMs: Posttranslational modifications; PUVA: 8 Methoxy-psoralen; RAGE: Advanced glycation end products; rhTM: Recombinant human soluble thrombomodulin; rTM: Recombinant human thrombomodulin; SASP: Senescence-associated secretory phenotype; SCF: Stem cell factor; SCs: Stem cells; SDF-1: Stromal cell-derived factor-1; SIRS: Systemic inflammatory response syndrome; sLPC: Stearoyl lysophosphatidylcholine; SP: Substance P; s-RAGE: Soluble RAGE; SS: Sézary syndrome; STAT1: Signal transducer and activator of transcription 1: TAC: Transplantation-associated coagulopathy; TAT-HMGB1A: TAT-labeled HMGB1 A-box-His6; T-ALL: T cell ALL; TBI: Total body irradiation; TIM-3: T cell immunoglobulin mucin-3; TIR: Toll/interleukin-1 receptor; TKIs: Tyrosine kinase inhibitors; TLR4: Toll-like receptor 4; TME: Tumor microenvironment; TNF-a: Tumor necrosis factor alpha; Treg cells: Regulatory T cells; Ub: Ubiquitin; UPS: Ubiquitin proteasome system; UTR: Untranslated region; VCR: Vincristine; VEGF: Vascular endothelial growth factor; VOD: Venoocclusive disease; VP-16: Etoposide

\section{Authors' contributions}

SLY wrote the manuscript, summarized tables. JL reviewed the manuscript and revised the manuscript. ZRX and ZPL reviewed the manuscript and prepared figures. JZ conceived the projects and revised the manuscript. All authors reviewed the manuscript and approved the final manuscript.

\section{Funding}

This work was funded by the National Natural Science Foundation of China (No. 81870105, 81770107, and 81920108004), Key Project of Science and Technology of Hunan Provincial Health Commission (No.20201921), and the National Key Research and Development Program of China (2018YFA0107800).

\section{Availability of data and materials}

Not applicable, all information in this review can be found in the reference list.

\section{Ethics approval and consent to participate}

No ethics approval was required for this review that did not involve patients or patient data.

\section{Consent for publication}

All authors consent to publication.

\section{Competing interests}

The authors declare that they have no competing interests.

Received: 14 May 2020 Accepted: 16 June 2020

Published online: 13 July 2020

\section{References}

1. Goodwin GH, Sanders C, Johns EW. A new group of chromatin-associated proteins with a high content of acidic and basic amino acids. Eur J Biochem. 1973;38(1):14-9.

2. Kang R, Chen R, Zhang Q, Hou W, Wu S, Cao L, et al. HMGB1 in health and disease. Mol Asp Med. 2014;40:1-116.

3. Andersson $\mathrm{U}$, Yang $\mathrm{H}$, Harris $\mathrm{H}$. High-mobility group box 1 protein (HMGB1) operates as an alarmin outside as well as inside cells. Semin Immunol. 2018; 38:40-8.

4. Stros M. HMGB proteins: interactions with DNA and chromatin. Biochim Biophys Acta. 2010;1799(1-2):101-13.

5. Li J, Kokkola R, Tabibzadeh S, Yang R, Ochani M, Qiang X, et al. Structural basis for the proinflammatory cytokine activity of high mobility group box 1. Molecular medicine (Cambridge, Mass). 2003;9(1-2):37-45.

6. Ellerman JE, Brown CK, de Vera M, Zeh HJ, Billiar T, Rubartelli A, et al. Masquerader: high mobility group box-1 and cancer. Clinical cancer research : an official journal of the American Association for Cancer Research. 2007;13(10):2836-48.

7. Ueda T, Chou H, Kawase T, Shirakawa H, Yoshida M. Acidic C-tail of HMGB1 is required for its target binding to nucleosome linker DNA and transcription stimulation. Biochemistry. 2004;43(30):9901-8.

8. Ling Y, Yang ZY, Yin T, Li L, Yuan WW, Wu HS, et al. Heparin changes the conformation of high-mobility group protein 1 and decreases its affinity toward receptor for advanced glycation endproducts in vitro. Int Immunopharmacol. 2011;11(2):187-93.

9. Li L, Ling Y, Huang M, Yin T, Gou SM, Zhan NY, et al. Heparin inhibits the inflammatory response induced by LPS and HMGB1 by blocking the binding of HMGB1 to the surface of macrophages. Cytokine. 2015; 72(1):36-42.

10. Diener KR, Al-Dasoogi N, Lousberg EL, Hayball JD. The multifunctional alarmin HMGB1 with roles in the pathophysiology of sepsis and cancer. Immunol Cell Biol. 2013;91(7):443-50.

11. Huttunen HJ, Fages C, Kuja-Panula J, Ridley AJ, Rauvala H. Receptor for advanced glycation end products-binding $\mathrm{COOH}$-terminal motif of amphoterin inhibits invasive migration and metastasis. Cancer Res. 2002; 62(16):4805-11.

12. Kwak MS, Kim HS, Lkhamsuren K, Kim YH, Han MG, Shin JM, et al. Peroxiredoxin-mediated disulfide bond formation is required for nucleocytoplasmic translocation and secretion of HMGB1 in response to inflammatory stimuli. Redox Biol. 2019;24:101203.

13. Bonaldi T, Talamo F, Scaffidi P, Ferrera D, Porto A, Bachi A, et al. Monocytic cells hyperacetylate chromatin protein HMGB1 to redirect it towards secretion. EMBO J. 2003;22(20):5551-60.

14. Youn JH, Shin JS. Nucleocytoplasmic shuttling of HMGB1 is regulated by phosphorylation that redirects it toward secretion. Journal of immunology (Baltimore, Md : 1950). 2006;177(11):7889-97.

15. Zhang X, Wheeler D, Tang Y, Guo L, Shapiro RA, Ribar TJ, et al. Calcium/ calmodulin-dependent protein kinase (CaMK) IV mediates nucleocytoplasmic shuttling and release of HMGB1 during lipopolysaccharide stimulation of macrophages. Journal of immunology (Baltimore, Md : 1950). 2008;181(7):5015-23.

16. Richard SA, Jiang Y, Xiang LH, Zhou S, Wang J, Su Z, et al. Post-translational modifications of high mobility group box 1 and cancer. Am J Transl Res. 2017;9(12):5181-96.

17. Siegers K, Bölter B, Schwarz JP, Böttcher UM, Guha S, Hartl FU. TRiC/CCT cooperates with different upstream chaperones in the folding of distinct protein classes. EMBO J. 2008;27(1):301. 
18. Lu B, Antoine DJ, Kwan K, Lundbäck P, Wähämaa $H$, Schierbeck $H$, et al. JAK/STAT1 signaling promotes HMGB1 hyperacetylation and nuclear translocation. Proc Natl Acad Sci U S A. 2014;111(8):3068-73.

19. Ito I, Fukazawa J, Yoshida M. Post-translational methylation of high mobility group box 1 (HMGB1) causes its cytoplasmic localization in neutrophils. J Biol Chem. 2007;282(22):16336-44.

20. Ramachandran C, Yau P, Bradbury EM, Shyamala G, Yasuda H, Walsh DA. Phosphorylation of high-mobility-group proteins by the calciumphospholipid-dependent protein kinase and the cyclic AMP-dependent protein kinase. J Biol Chem. 1984;259(21):13495-503.

21. Oh YJ, Youn JH, Ji Y, Lee SE, Lim KJ, Choi JE, et al. HMGB1 is phosphorylated by classical protein kinase $\mathrm{C}$ and is secreted by a calcium-dependent mechanism. Journal of immunology (Baltimore, Md : 1950). 2009;182(9): 5800-9.

22. Li Y, Xie J, Li X, Fang J. Poly (ADP-ribosylation) of HMGB1 facilitates its acetylation and promotes HMGB1 translocation-associated chemotherapyinduced autophagy in leukaemia cells. Oncol Lett. 2020;19(1):368-78.

23. Kong $Q$, Li Y, Liang $Q$, Xie J, Li X, Fang J. SIRT6-PARP1 is involved in HMGB1 polyADP-ribosylation and acetylation and promotes chemotherapy-induced autophagy in leukemia. Cancer biology \& therapy. 2020;21(4):320-31.

24. Davis K, Banerjee S, Friggeri A, Bell C, Abraham E, Zerfaoui M. Poly(ADPribosyl)ation of high mobility group box 1 (HMGB1) protein enhances inhibition of efferocytosis. Molecular medicine (Cambridge, Mass). 2012; 18(1):359-69.

25. Huang H, Nace GW, McDonald KA, Tai S, Klune JR, Rosborough BR, et al. Hepatocyte-specific high-mobility group box 1 deletion worsens the injury in liver ischemia/reperfusion: a role for intracellular high-mobility group box 1 in cellular protection. Hepatology (Baltimore, Md). 2014;59(5):1984-97.

26. Kim YH, Kwak MS, Park JB, Lee SA, Choi JE, Cho HS, et al. N-linked glycosylation plays a crucial role in the secretion of HMGB1. J Cell Sci. 2016; 129(1):29-38.

27. Song L, Luo ZQ. Post-translational regulation of ubiquitin signaling. J Cell Biol. 2019;218(6):1776-86.

28. Ferreri AJ, Illerhaus G, Zucca E, Cavalli F. Flows and flaws in primary central nervous system lymphoma. Nature reviews Clinical oncology. 2010;7(8):doi: 10.1038/nrclinonc. 2010.9-c1; author reply doi:10:1038/nrclinonc.2010.9-c2.

29. Gao D, Lv AE, Li HP, Han DH, Zhang YP. LncRNA MALAT-1 Elevates HMGB1 to Promote autophagy resulting in inhibition of tumor cell apoptosis in multiple myeloma. J Cell Biochem. 2017;118(10):3341-8.

30. Roy M, Liang L, Xiao X, Peng Y, Luo Y, Zhou W, et al. Lycorine downregulates HMGB1 to inhibit autophagy and enhances bortezomib activity in multiple myeloma. Theranostics. 2016;6(12):2209-24.

31. Schiraldi M, Raucci A, Muñoz LM, Livoti E, Celona B, Venereau E, et al. HMGB1 promotes recruitment of inflammatory cells to damaged tissues by forming a complex with CXCL12 and signaling via CXCR4. J Exp Med. 2012; 209(3):551-63.

32. Venereau E, Casalgrandi M, Schiraldi M, Antoine DJ, Cattaneo A, De Marchis $F$, et al. Mutually exclusive redox forms of HMGB1 promote cell recruitment or proinflammatory cytokine release. J Exp Med. 2012;209(9):1519-28.

33. Biscetti F, Ghirlanda G, Flex A. Therapeutic potential of high mobility group box-1 in ischemic injury and tissue regeneration. Curr Vasc Pharmacol. 2011; 9(6):677-81.

34. Venereau E, Schiraldi M, Uguccioni M, Bianchi ME. HMGB1 and leukocyte migration during trauma and sterile inflammation. Mol Immunol. 2013;55(1): 76-82.

35. Yang $H$, Wang $H$, Ju Z, Ragab AA, Lundbäck P, Long W, et al. MD-2 is required for disulfide HMGB1-dependent TLR4 signaling. J Exp Med. 2015; 212(1):5-14.

36. Kazama H, Ricci JE, Herndon JM, Hoppe G, Green DR, Ferguson TA. Induction of immunological tolerance by apoptotic cells requires caspasedependent oxidation of high-mobility group box-1 protein. Immunity. 2008; 29(1):21-32.

37. Jube S, Rivera ZS, Bianchi ME, Powers A, Wang E, Pagano I, et al. Cancer cell secretion of the DAMP protein HMGB1 supports progression in malignant mesothelioma. Cancer Res. 2012;72(13):3290-301.

38. Gardella S, Andrei C, Ferrera D, Lotti LV, Torrisi MR, Bianchi ME, et al. The nuclear protein HMGB1 is secreted by monocytes via a non-classical, vesicle-mediated secretory pathway. EMBO Rep. 2002;3(10):995-1001.

39. Lotze MT, Zeh HJ, Rubartelli A, Sparvero L, Amoscato AA, Washburn NR, et al. The grateful dead: damage-associated molecular pattern molecules and reduction/oxidation regulate immunity. Immunol Rev. 2007;220:60-81.
40. Li G, Tang D, Lotze MT. Ménage à Trois in stress: DAMPs, redox and autophagy. Semin Cancer Biol. 2013;23(5):380-90.

41. Li G, Liang X, Lotze MT. HMGB1: The central cytokine for all lymphoid cells. Front Immunol. 2013;4:68.

42. Hori O, Brett J, Slattery T, Cao R, Zhang J, Chen JX, et al. The receptor for advanced glycation end products (RAGE) is a cellular binding site for amphoterin. Mediation of neurite outgrowth and co-expression of rage and amphoterin in the developing nervous system. J Biol Chem. 1995;270(43):25752-61.

43. Singh R, Barden A, Mori T, Beilin L. Advanced glycation end-products: a review. Diabetologia. 2001;44(2):129-46.

44. Liu L, Gao F, Ye Y, Chen Z, Dai Y, Zhao P, et al. Influence of HMGB1/MAPK $m$-TOR signaling pathway on cell autophagy and chemotherapy resistance in K562 cells. Zhong nan da xue xue bao Yi xue ban = Journal of Central South University Medical sciences. 2016;41(10):1016-23.

45. Mou K, Liu W, Han D, Li P. HMGB1/RAGE axis promotes autophagy and protects keratinocytes from ultraviolet radiation-induced cell death. J Dermatol Sci. 2017:85(3):162-9.

46. Taguchi A, Blood DC, del Toro G, Canet A, Lee DC, Qu W, et al. Blockade of RAGE-amphoterin signalling suppresses tumour growth and metastases. Nature. 2000;405(6784):354-60.

47. Sim MY, Yuen JSP, Go ML. Anti-survivin effect of the small molecule inhibitor YM155 in RCC cells is mediated by time-dependent inhibition of the NF-KB pathway. Sci Rep. 2018:8(1):10289.

48. Sims GP, Rowe DC, Rietdijk ST, Herbst R, Coyle AJ. HMGB1 and RAGE in inflammation and cancer. Annu Rev Immunol. 2010:28:367-88.

49. Wang G, Liu L, Zhang Y, Han D, Liu J, Xu J, et al. Activation of PPARY attenuates LPS-induced acute lung injury by inhibition of HMGB1-RAGE levels. Eur J Pharmacol. 2014;726:27-32.

50. Kawai T, Akira S. The role of pattern-recognition receptors in innate immunity: update on Toll-like receptors. Nat Immunol. 2010;11(5):373-84.

51. Pradere JP, Dapito DH, Schwabe RF. The Yin and Yang of toll-like receptors in cancer. Oncogene. 2014;33(27):3485-95.

52. Velegraki M, Papakonstanti E, Mavroudi I, Psyllaki M, Tsatsanis C, Oulas A, et al. Impaired clearance of apoptotic cells leads to HMGB1 release in the bone marrow of patients with myelodysplastic syndromes and induces TLR4-mediated cytokine production. Haematologica. 2013;98(8): 1206-15.

53. Bianchi ME. HMGB1 loves company. J Leukoc Biol. 2009;86(3):573-6.

54. Ivanov S, Dragoi AM, Wang X, Dallacosta C, Louten J, Musco G, et al. A novel role for HMGB1 in TLR9-mediated inflammatory responses to CpGDNA. Blood. 2007;110(6):1970-81.

55. Irie Y, Tsubota M, Ishikura H, Sekiguchi F, Terada Y, Tsujiuchi T, et al. Macrophage-derived HMGB1 as a pain mediator in the early stage of acute pancreatitis in mice: targeting RAGE and CXCL12/CXCR4 axis. Journal of neuroimmune pharmacology : the official journal of the Society on Neurolmmune Pharmacology. 2017;12(4):693-707.

56. Feng Y, Broder CC, Kennedy PE, Berger EA. Pillars article: HIV-1 entry cofactor: functional CDNA cloning of a seven-transmembrane, G proteincoupled receptor. Science. 1996. 272: 872-877. Journal of immunology (Baltimore, Md : 1950). 2011;186(11):6076-81.

57. Ratajczak MZ, Zuba-Surma E, Kucia M, Reca R, Wojakowski W, Ratajczak J. The pleiotropic effects of the SDF-1-CXCR4 axis in organogenesis, regeneration and tumorigenesis. Leukemia. 2006;20(11):1915-24.

58. Zhou W, Guo S, Liu M, Burow ME, Wang G. Targeting CXCL12/CXCR4 axis in tumor immunotherapy. Curr Med Chem. 2019;26(17):3026-41.

59. Teicher BA, Fricker SP. CXCL12 (SDF-1)/CXCR4 pathway in cancer. Clinical cancer research : an official journal of the American Association for Cancer Research. 2010;16(11):2927-31.

60. Wang $Y$, Xie $Y$, Williams J, Hang $Y$, Richter $L$, Becker $M$, et al. Use of polymeric CXCR4 inhibitors as siRNA delivery vehicles for the treatment of acute myeloid leukemia. Cancer Gene Ther. 2020;27(1-2):45-55.

61. Landry B, Gül-Uludağ H, Plianwong S, Kucharski C, Zak Z, Parmar MB, et al. Targeting CXCR4/SDF-1 axis by lipopolymer complexes of siRNA in acute myeloid leukemia. Journal of controlled release : official journal of the Controlled Release Society. 2016;224:8-21.

62. Tirone M, Tran NL, Ceriotti C, Gorzanelli A, Canepari M, Bottinelli R, et al. High mobility group box 1 orchestrates tissue regeneration via CXCR4. J Exp Med. 2018;215(1):303-18.

63. Fassi EMA, Sgrignani J, D'Agostino G, Cecchinato V, Garofalo M, Grazioso G, et al. Oxidation State Dependent conformational changes of HMGB1 
regulate the formation of the CXCL12/HMGB1 heterocomplex. Computational and structural biotechnology journal. 2019;17:886-94.

64. Kew RR, Penzo M, Habiel DM, Marcu KB. The IKKa-dependent NF-KB p52/ RelB noncanonical pathway is essential to sustain a CXCL12 autocrine loop in cells migrating in response to HMGB1. Journal of immunology (Baltimore, Md : 1950). 2012;188(5):2380-6.

65. Freeman GJ, Casasnovas JM, Umetsu DT, DeKruyff RH. TIM genes: a family of cell surface phosphatidylserine receptors that regulate innate and adaptive immunity. Immunol Rev. 2010;235(1):172-89.

66. Chiba S, Baghdadi M, Akiba H, Yoshiyama H, Kinoshita I, Dosaka-Akita H, et al. Tumor-infiltrating DCs suppress nucleic acid-mediated innate immune responses through interactions between the receptor TIM-3 and the alarmin HMGB1. Nat Immunol. 2012:13(9):832-42.

67. Patel J, Bozeman EN, Selvaraj P. Taming dendritic cells with TIM-3: another immunosuppressive strategy used by tumors. Immunotherapy. 2012;4(12):1795-8,

68. Wolf $Y$, Anderson AC, Kuchroo VK. TIM3 comes of age as an inhibitory receptor. Nat Rev Immunol. 2020;20(3):173-85.

69. Yasinska IM, Gonçalves Silva I, Sakhnevych SS, Ruegg L, Hussain R, Siligardi G, et al. High mobility group box 1 (HMGB1) acts as an "alarmin" to promote acute myeloid leukaemia progression. Oncoimmunology. 2018;7(6):e1438109.

70. Deneault E, Cellot S, Faubert A, Laverdure JP, Fréchette M, Chagraoui J, et al. A functional screen to identify novel effectors of hematopoietic stem cell activity. Cell. 2009;137(2):369-79.

71. Schrumpfová PP, Fojtová M, Mokroš P, Grasser KD, Fajkus J. Role of HMGB proteins in chromatin dynamics and telomere maintenance in Arabidopsis thaliana. Curr Protein Pept Sci. 2011;12(2):105-11.

72. Jayaraman L, Moorthy NC, Murthy KG, Manley JL, Bustin M, Prives C. High mobility group protein-1 (HMG-1) is a unique activator of p53. Genes Dev. 1998;12(4):462-72.

73. Travers AA. Priming the nucleosome: a role for HMGB proteins? EMBO Rep. 2003;4(2):131-6.

74. Altmann S, Lange S, Pommerencke J, Murua Escobar H, Bullerdiek J, Nolte I, et al. High Mobility Group Box 1-Protein expression in canine haematopoietic cells and influence on canine peripheral blood mononuclear cell proliferative activity. Vet Immunol Immunopathol. 2008; 126(3-4):367-72

75. Ratajczak MZ, Adamiak M, Thapa A, Bujko K, Brzezniakiewicz-Janus K, Lenkiewicz AM. NLRP3 inflammasome couples purinergic signaling with activation of the complement cascade for the optimal release of cells from bone marrow. Leukemia. 2019;33(4):815-25.

76. Tagami K, Yujiri T, Tanimura A, Mitani N, Nakamura Y, Ariyoshi K, et al. Elevation of serum high-mobility group box 1 protein during granulocyte colony-stimulating factor-induced peripheral blood stem cell mobilisation. Br J Haematol. 2006;135(4):567-9.

77. Rameshwar P, Ganea D, Gascón P. In vitro stimulatory effect of substance P on hematopoiesis. Blood. 1993;81(2):391-8.

78. Rameshwar P, Gascón P. Induction of negative hematopoietic regulators by neurokinin-A in bone marrow stroma. Blood. 1996;88(1):98-106.

79. Gergues M, Nagula V, Bliss SA, Eljarrah A, Ayer S, Gnanavel N, et al. Neuroimmune/Hematopoietic Axis with Distinct Regulation by the HighMobility Group Box 1 in Association with Tachykinin Peptides. Journal of immunology (Baltimore, Md : 1950). 2020;204(4):879-91.

80. Ho MS, Medcalf RL, Livesey SA, Traianedes K. The dynamics of adult haematopoiesis in the bone and bone marrow environment. Br J Haematol. 2015;170(4):472-86.

81. Shafat MS, Gnaneswaran B, Bowles KM, Rushworth SA. The bone marrow microenvironment - Home of the leukemic blasts. Blood Rev. 2017;31(5):277-86.

82. Tian X, Shen H, Li Z, Wang T, Wang S. Tumor-derived exosomes, myeloidderived suppressor cells, and tumor microenvironment. J Hematol Oncol. 2019;12(1):84

83. Lv M, Wang K, Huang XJ. Myeloid-derived suppressor cells in hematological malignancies: friends or foes. J Hematol Oncol. 2019;12(1):105.

84. Palumbo GA, Parrinello NL, Giallongo C, D'Amico E, Zanghì A, Puglisi F, et al. Monocytic myeloid derived suppressor cells in hematological malignancies. International journal of molecular sciences. 2019;20(21).

85. Parker KH, Sinha P, Horn LA, Clements VK, Yang H, Li J, et al. HMGB1 enhances immune suppression by facilitating the differentiation and suppressive activity of myeloid-derived suppressor cells. Cancer Res. 2014;74(20):5723-33.

86. Son M, Santiago-Schwarz F, Al-Abed Y, Diamond B. C1q limits dendritic cell differentiation and activation by engaging LAIR-1. Proc Natl Acad Sci U S A. 2012;109(46):E3160-7.
87. Son M, Porat A, He M, Suurmond J, Santiago-Schwarz F, Andersson U, et al. $\mathrm{Clq}$ and $\mathrm{HMGB} 1$ reciprocally regulate human macrophage polarization. Blood. 2016;128(18):2218-28.

88. Charoonpatrapong K, Shah R, Robling AG, Alvarez M, Clapp DW, Chen S, et al. HMGB1 expression and release by bone cells. J Cell Physiol. 2006; 207(2):480-90

89. Gao Q, Li F, Wang S, Shen Z, Cheng S, Ping Y, et al. A cycle involving HMGB1, IFN- $\gamma$ and dendritic cells plays a putative role in anti-tumor immunity. Cell Immunol. 2019;343:103850.

90. Lee MW, Ryu S, Kim DS, Lee JW, Sung KW, Koo HH, et al. Mesenchymal stem cells in suppression or progression of hematologic malignancy: current status and challenges. Leukemia. 2019;33(3):597-611.

91. Wang J, Liu X, Qiu Y, Shi Y, Cai J, Wang B, et al. Cell adhesion-mediated mitochondria transfer contributes to mesenchymal stem cell-induced chemoresistance on T cell acute lymphoblastic leukemia cells. J Hematol Oncol. 2018;11(1):11.

92. Feng L, Xue D, Chen E, Zhang W, Gao X, Yu J, et al. HMGB1 promotes the secretion of multiple cytokines and potentiates the osteogenic differentiation of mesenchymal stem cells through the Ras/MAPK signaling pathway. Experimental and therapeutic medicine. 2016;12(6):3941-7.

93. Ji J, Fu T, Dong C, Zhu W, Yang J, Kong X, et al. Targeting HMGB1 by ethyl pyruvate ameliorates systemic lupus erythematosus and reverses the senescent phenotype of bone marrow-mesenchymal stem cells. Aging. 2019;11(13):4338-53

94. Salminen A, Kauppinen A, Kaarniranta K. Emerging role of NF-KB signaling in the induction of senescence-associated secretory phenotype (SASP). Cell Signal. 2012;24(4):835-45.

95. Davalos AR, Kawahara M, Malhotra GK, Schaum N, Huang J, Ved U, et al. p53-dependent release of Alarmin HMGB1 is a central mediator of senescent phenotypes. J Cell Biol. 2013;201(4):613-29.

96. Han Y, Yuan F, Deng C, He F, Zhang Y, Shen H, et al. Metformin decreases LPS-induced inflammatory response in rabbit annulus fibrosus stem/ progenitor cells by blocking HMGB1 release. Aging. 2019;11(22):10252-65.

97. Coppé JP, Desprez PY, Krtolica A, Campisi J. The senescence-associated secretory phenotype: the dark side of tumor suppression. Annu Rev Pathol. 2010;5:99-118.

98. Davalos AR, Coppe JP, Campisi J, Desprez PY. Senescent cells as a source of inflammatory factors for tumor progression. Cancer Metastasis Rev. 2010; 29(2):273-83.

99. Kam AYF, Piryani SO, McCall CM, Park HS, Rizzieri DA, Doan PL. Targeting high mobility group box-1 (HMGB1) promotes cell death in myelodysplastic syndrome. Clinical cancer research : an official journal of the American Association for Cancer Research. 2019;25(13):4155-67.

100. Nasr R, Lallemand-Breitenbach V, Zhu J, Guillemin MC, de Thé H. Therapyinduced PML/RARA proteolysis and acute promyelocytic leukemia cure. Clinical cancer research : an official journal of the American Association for Cancer Research. 2009;15(20):6321-6.

101. Yang L, Chai W, Wang Y, Cao L, Xie M, Yang M, et al. Reactive oxygen species regulate the differentiation of acute promyelocytic leukemia cells through HMGB1-mediated autophagy. Am J Cancer Res. 2015;5(2):714-25.

102. Luesink M, Pennings JL, Wissink WM, Linssen PC, Muus P, Pfundt R, et al. Chemokine induction by all-trans retinoic acid and arsenic trioxide in acute promyelocytic leukemia: triggering the differentiation syndrome. Blood. 2009;114(27):5512-21.

103. Tang $L$, Chai W, Ye F, Yu Y, Cao L, Yang M, et al. HMGB1 promotes differentiation syndrome by inducing hyperinflammation via MEKJERK signaling in acute promyelocytic leukemia cells. Oncotarget. 2017;8(16):27314-27.

104. Melloni E, Sparatore B, Patrone M, Pessino A, Passalacqua M, Pontremoli S. Extracellular release of the 'differentiation enhancing factor', a HMG1 protein type, is an early step in murine erythroleukemia cell differentiation. FEBS Lett. 1995;368(3):466-70.

105. Sparatore B, Melloni E, Patrone M, Passalacqua M, Pontremoli S. A 6 kDa protein homologous to the $\mathrm{N}$-terminus of the HMG1 protein promoting stimulation of murine erythroleukemia cell differentiation. FEBS Lett. 1996; 386(2-3):95-8

106. Sparatore B, Passalacqua M, Patrone M, Melloni E, Pontremoli S. Extracellular high-mobility group 1 protein is essential for murine erythroleukaemia cell differentiation. The Biochemical journal. 1996; 320 ( Pt 1)(Pt 1):253-256.

107. Passalacqua M, Zicca A, Sparatore B, Patrone M, Melloni E, Pontremoli S. Secretion and binding of HMG1 protein to the external surface of the 
membrane are required for murine erythroleukemia cell differentiation. FEBS Lett. 1997;400(3):275-9.

108. Liu L, Ren W, Chen K. MiR-34a promotes apoptosis and inhibits autophagy by targeting HMGB1 in acute myeloid leukemia cells. Cellular physiology and biochemistry : international journal of experimental cellular physiology, biochemistry, and pharmacology. 2017:41(5):1981-92.

109. Lu F, Zhang J, Ji M, Li P, Du Y, Wang H, et al. miR-181b increases drug sensitivity in acute myeloid leukemia via targeting HMGB1 and Mcl-1. Int J Oncol. 2014;45(1):383-92

110. Zhang Y, Liu Y, Xu X. Upregulation of miR-142-3p Improves drug sensitivity of acute myelogenous leukemia through reducing P-glycoprotein and repressing autophagy by targeting HMGB1. Transl Oncol. 2017;10(3):410-8.

111. Tan JY, Zhao F, Deng SX, Zhu HC, Gong Y, Wang W. Glycyrrhizin affects monocyte migration and apoptosis by blocking HMGB1 signaling. Mol Med Rep. 2018;17(4):5970-5.

112. Ola MS, Nawaz M, Ahsan $\mathrm{H}$. Role of Bcl-2 family proteins and caspases in the regulation of apoptosis. Mol Cell Biochem. 2011;351(1-2):41-58.

113. Tenev T, Bianchi K, Darding M, Broemer M, Langlais C, Wallberg F, et al. The Ripoptosome, a signaling platform that assembles in response to genotoxic stress and loss of IAPs. Mol Cell. 2011;43(3):432-48.

114. Liu Y, Chen P, Xu L, Ouyang M, Wang D, Tang D, et al. Extracellular HMGB1 prevents necroptosis in acute myeloid leukemia cells. Biomedicine \& pharmacotherapy $=$ Biomedecine \& pharmacotherapie. 2019;112:108714.

115. Chen $X$, Wang $Y$, Liu J, Xu P, Zhang XM, Tian YY, et al. Synergistic effect of HMGB1 knockdown and cordycepin in the K562 human chronic myeloid leukemia cell line. Mol Med Rep. 2015;12(3):4462-8.

116. Sato A, Mizobuchi Y, Nakajima K, Shono K, Fujihara T, Kageji T, et al. Blocking COX-2 induces apoptosis and inhibits cell proliferation via the Akt/ survivin- and Akt/ID3 pathway in low-grade-glioma. J Neuro-Oncol. 2017; 132(2):231-8

117. Xu Z, Jin Y, Yan H, Gao Z, Xu B, Yang B, et al. High-mobility group box 1 protein-mediated necroptosis contributes to dasatinib-induced cardiotoxicity. Toxicol Lett. 2018;296:39-47.

118. Song S, Lee JY, Ermolenko L, Mazumder A, Ji S, Ryu H, et al. Tetrahydrobenzimidazole TMQ0153 triggers apoptosis, autophagy and necroptosis crosstalk in chronic myeloid leukemia. Cell Death Dis. 2020; 11(2):109.

119. Zhao $M$, Yang $M$, Yang $L, Y u Y$, Xie $M$, Zhu S, et al. HMGB1 regulates autophagy through increasing transcriptional activities of JNK and ERK in human myeloid leukemia cells. BMB Rep. 2011:44(9):601-6.

120. Yu Y, Xie M, He YL, Xu WQ, Zhu S, Cao LZ. Role of high mobility group box 1 in adriamycin-induced apoptosis in leukemia K562 cells. Ai zheng = Aizheng = Chinese journal of cancer. 2008;27(9):929-33.

121. Hunger SP, Mullighan CG. Acute Lymphoblastic Leukemia in Children. N Engl J Med. 2015:373(16):1541-52.

122. Kang R, Tang DL, Cao LZ, Yu Y, Zhang GY, Xiao XZ. High mobility group box 1 is increased in children with acute lymphocytic leukemia and stimulates the release of tumor necrosis factor-alpha in leukemic cell. Zhonghua er ke za zhi $=$ Chinese journal of pediatrics. 2007:45(5):329-33.

123. Kong $Q, X u L H, X u$ W, Fang JP, Xu HG. HMGB1 translocation is involved in the transformation of autophagy complexes and promotes chemoresistance in leukaemia. Int J Oncol. 2015;47(1):161-70.

124. Dahlhaus M, Schult C, Lange S, Freund M, Junghanss C. MicroRNA 181a influences the expression of HMGB1 and CD4 in acute Leukemias. Anticancer Res. 2013;33(2):445-52.

125. Fucikova J, Kralikova P, Fialova A, Brtnicky T, Rob L, Bartunkova J, et al. Human tumor cells killed by anthracyclines induce a tumor-specific immune response. Cancer Res. 2011;71(14):4821-33.

126. Meyer A, Staratschek-Jox A, Springwald A, Wenk H, Wolf J, Wickenhauser C, et al. Non-Hodgkin lymphoma expressing high levels of the dangersignalling protein HMGB1. Leuk Lymphoma. 2008;49(6):1184-9.

127. Jia L, Clear A, Liu FT, Matthews J, Uddin N, McCarthy A, et al. Extracellular HMGB1 promotes differentiation of nurse-like cells in chronic lymphocytic leukemia. Blood. 2014;123(11):1709-19.

128. Wilcox RA. Cutaneous T-cell lymphoma: 2017 update on diagnosis, riskstratification, and management. Am J Hematol. 2017;92(10):1085-102.

129. Girardi M, Heald PW, Wilson LD. The pathogenesis of mycosis fungoides. N Engl J Med. 2004;350(19):1978-88

130. Senda N, Miyagaki T, Kamijo H, Nakajima R, Oka T, Takahashi N, et al. Increased HMGB1 levels in lesional skin and sera in patients with cutaneous T-cell lymphoma. European journal of dermatology : EJD. 2018;28(5):621-7.
131. Vowels BR, Lessin SR, Cassin M, Jaworsky C, Benoit B, Wolfe JT, et al. Th2 cytokine mRNA expression in skin in cutaneous T-cell lymphoma. The Journal of investigative dermatology. 1994;103(5):669-73.

132. Asadullah K, Döcke WD, Haeussler A, Sterry W, Volk HD. Progression of mycosis fungoides is associated with increasing cutaneous expression of interleukin-10 mRNA. The Journal of investigative dermatology. 1996;107(6):833-7.

133. Oka T, Sugaya M, Takahashi N, Nakajima R, Otobe S, Kabasawa M, et al. Increased interleukin-19 expression in cutaneous T-cell lymphoma and atopic dermatitis. Acta Derm Venereol. 2017;97(10):1172-7.

134. Fredholm S, Gjerdrum LM, Willerslev-Olsen A, Petersen DL, Nielsen I, Kauczok CS, et al. STAT3 activation and infiltration of eosinophil granulocytes in mycosis fungoides. Anticancer Res. 2014;34(10):5277-86.

135. Mao XJ, Wang GF, Chen ZJ, Wang LN, Zhang JB, Wang HL. Expression of HMGB1 and its clinical significance in T-cell lymphoma. Asian Pacific journal of cancer prevention: APJCP. 2012;13(11):5569-71.

136. Zhao T, Ren H, Wang X, Liu P, Yan F, Jiang W, et al. Rituximab-induced HMGB1 release is associated with inhibition of STAT3 activity in human diffuse large B-cell lymphoma. Oncotarget. 2015;6(29):27816-31.

137. Zhang T, Guan XW, Gribben JG, Liu FT, Jia L. Blockade of HMGB1 signaling pathway by ethyl pyruvate inhibits tumor growth in diffuse large B-cell lymphoma. Cell Death Dis. 2019;10(5):330.

138. He SJ, Cheng J, Feng X, Yu Y, Tian L, Huang Q. The dual role and therapeutic potential of high-mobility group box 1 in cancer. Oncotarget. 2017;8(38):64534-50.

139. Dejean E, Foisseau M, Lagarrigue F, Lamant L, Prade N, Marfak A, et al. ALK+ ALCLs induce cutaneous, HMGB-1-dependent IL-8/CXCL8 production by keratinocytes through NF-KB activation. Blood. 2012;119(20):4698-707.

140. Kimura R, Mori N. Abundant expression of HMGB1 in human T-cell lymphotropic virus type l-infected T-cell lines and high plasma levels of HMGB1 in patients with adult T-cell leukemia. Oncol Lett. 2014;7(4):1239-42.

141. Proietti FA, Carneiro-Proietti AB, Catalan-Soares BC, Murphy EL. Global epidemiology of HTLV-I infection and associated diseases. Oncogene. 2005; 24(39):6058-68.

142. Zhang CG, Wang H, Niu ZG, Zhang JJ, Yin MM, Gao ZT, et al. Tax is involved in up-regulation of HMGB1 expression levels by interaction with C/EBP. Asian Pacific journal of cancer prevention : APJCP. 2013;14(1):359-65.

143. Guo X, He D, Zhang E, Chen J, Chen Q, Li Y, et al. HMGB1 knockdown increases MM cell vulnerability by regulating autophagy and DNA damage repair. Journal of experimental \& clinical cancer research : CR. 2018;37(1):205

144. Kuczma M, Ding ZC, Zhou G. Immunostimulatory Effects of Melphalan and usefulness in adoptive cell therapy with antitumor CD4+ T cells. Crit Rev Immunol. 2016;36(2):179-91.

145. D'Eliseo D, Di Renzo L, Santoni A, Velotti F. Docosahexaenoic acid (DHA) promotes immunogenic apoptosis in human multiple myeloma cells, induces autophagy and inhibits STAT3 in both tumor and dendritic cells. Genes \& cancer. 2017;8(1-2):426-37.

146. Nomura $S$, Ito $T$, Yoshimura $H$, Hotta $M$, Nakanishi $T$, Fujita $S$, et al. Evaluation of thrombosis-related biomarkers before and after therapy in patients with multiple myeloma. Journal of blood medicine. 2018;9:1-7.

147. Inoue $Y$, Saito T, Tsuruoka Y, Sato K, Nishio Y, Suzuki Y, et al. Recombinant thrombomodulin improved Stevens-Johnson syndrome with high serum high-mobility group-B1 DNA-binding protein induced by lenalidomide administered to treat multiple myeloma. Thromb Res. 2013;132(4):493-4

148. Ullah TR. The role of CXCR4 in multiple myeloma: Cells' journey from bone marrow to beyond. Journal of bone oncology. 2019;17:100253.

149. Kanakry CG, Fuchs EJ, Luznik L. Modern approaches to HLA-haploidentical blood or marrow transplantation. Nat Rev Clin Oncol. 2016;13(2):132.

150. Yujiri T, Tagami K, Tanaka Y, Mitani N, Nakamura Y, Ariyoshi K, et al. Increased serum levels of high-mobility group box 1 protein in patients who developed acute graft-versus-host disease after allogeneic hematopoietic stem cell transplantation. Eur J Haematol. 2010;85(4):366-7.

151. Xu YJ, Li L, Chen Y, Fu B, Wu DS, Li XL, et al. Role of HMGB1 in regulation of STAT3 expression in CD4(+) T cells from patients with aGVHD after allogeneic hematopoietic stem cell transplantation. Clinical immunology (Orlando, Fla). 2015;161(2):278-83.

152. Kornblit B, Masmas T, Petersen SL, Madsen HO, Heilmann C, Schejbel L, et al. Association of HMGB1 polymorphisms with outcome after allogeneic hematopoietic cell transplantation. Biology of blood and marrow transplantation : journal of the American Society for Blood and Marrow Transplantation. 2010;16(2):239-52. 
153. Im KI, Kim N, Lim JY, Nam YS, Lee ES, Kim EJ, et al. The free radical scavenger NecroX-7 attenuates acute graft-versus-host disease via reciproca regulation of Th1/regulatory $T$ cells and inhibition of HMGB1 release. Journal of immunology (Baltimore, Md : 1950). 2015;194(11):5223-32.

154. Nomura S, Maeda Y, Ishii K, Katayama Y, Yagi H, Fujishima N, et al. Relationship between HMGB1 and PAl-1 after allogeneic hematopoietic stem cell transplantation. Journal of blood medicine. 2016;7:1-4.

155. Inoue Y, Matsunawa M, Sano F, Miura I. Efficacy of recombinant human soluble thrombomodulin in treating disseminated intravascular coagulation complicating allogeneic hematopoietic stem cell transplantation. Acta Haematol. 2018;140(2):121-7.

156. Coppard C, Hannani D, Humbert M, Gauthier V, Plumas J, Merlin E, et al. In vitro PUVA treatment triggers calreticulin exposition and HMGB1 release by dying T lymphocytes in GVHD: New insights in extracorporeal photopheresis. J Clin Apher. 2019:34(4):450-60.

157. Wu K, Feng J, Xiu Y, Li Z, Lin Z, Zhao H, et al. V $\delta 2 T$ cell subsets, defined by PD-1 and TIM-3 expression, present varied cytokine responses in acute myeloid leukemia patients. Int Immunopharmacol. 2020;80:106122.

158. Pan B, Chen D, Huang J, Wang R, Feng B, Song H, et al. HMGB1-mediated autophagy promotes docetaxel resistance in human lung adenocarcinoma. Mol Cancer. 2014;13:165

159. Wang L, Zhang H, Sun M, Yin Z, Qian J. High mobility group box 1mediated autophagy promotes neuroblastoma cell chemoresistance. Oncol Rep. 2015;34(6):2969-76.

160. Huang J, Ni J, Liu K, Yu Y, Xie M, Kang R, et al. HMGB1 promotes drug resistance in osteosarcoma. Cancer Res. 2012:72(1):230-8.

161. Rabik CA, Dolan ME. Molecular mechanisms of resistance and toxicity associated with platinating agents. Cancer Treat Rev. 2007;33(1):9-23.

162. Green DR, Levine B. To be or not to be? How selective autophagy and cell death govern cell fate. Cell. 2014;157(1):65-75.

163. Li X, Zhou Y, Li Y, Yang L, Ma Y, Peng X, et al. Autophagy: A novel mechanism of chemoresistance in cancers. Biomedicine \& pharmacotherapy = Biomedecine \& pharmacotherapie. 2019;119:109415.

164. Heine S, Kleih M, Giménez N, Böpple K, Ott G, Colomer D, et al. Cyclin D1-CDK4 activity drives sensitivity to bortezomib in mantle cell lymphoma by blocking autophagy-mediated proteolysis of NOXA. J Hematol Oncol. 2018;11(1):112.

165. Sun X, Tang D. HMGB1-dependent and -independent autophagy. Autophagy. 2014;10(10):1873-6.

166. Sehgal AR, Konig H, Johnson DE, Tang D, Amaravadi RK, Boyiadzis M, et al. You eat what you are: autophagy inhibition as a therapeutic strategy in leukemia. Leukemia. 2015;29(3):517-25.

167. Liu L, Yang M, Kang R, Wang Z, Zhao Y, Yu Y, et al. DAMP-mediated autophagy contributes to drug resistance. Autophagy. 2011;7(1):112-4.

168. Tang D, Kang R, Livesey KM, Kroemer G, Billiar TR, Van Houten B, et al. Highmobility group box 1 is essential for mitochondrial quality control. Cell Metab. 2011;13(6):701-11.

169. Kang R, Livesey KM, Zeh HJ 3rd, Lotze MT, Tang D. Metabolic regulation by HMGB1-mediated autophagy and mitophagy. Autophagy. 2011;7(10):1256-8.

170. Yang L, Yu Y, Kang R, Yang M, Xie M, Wang Z, et al. Up-regulated autophagy by endogenous high mobility group box-1 promotes chemoresistance in leukemia cells. Leuk Lymphoma. 2012;53(2):315-22.

171. Shibutani S, Okazaki H, Iwata H. Dynamin-dependent amino acid endocytosis activates mechanistic target of rapamycin complex 1 (mTORC1). J Biol Chem. 2017;292(44):18052-61.

172. Huang CY, Chiang SF, Chen WT, Ke TW, Chen TW, You YS, et al. HMGB1 promotes ERK-mediated mitochondrial Drp1 phosphorylation for chemoresistance through RAGE in colorectal cancer. Cell Death Dis. 2018;9(10):1004

173. Taylor RC, Cullen SP, Martin SJ. Apoptosis: controlled demolition at the cellular level. Nat Rev Mol Cell Biol. 2008;9(3):231-41.

174. Lee JJ, Park IH, Rhee WJ, Kim HS, Shin JS. HMGB1 modulates the balance between senescence and apoptosis in response to genotoxic stress. FASEB journal : official publication of the Federation of American Societies for Experimental Biology. 2019;33(10):10942-53.

175. Liu L, Yang M, Kang R, Wang Z, Zhao Y, Yu Y, et al. HMGB1-induced autophagy promotes chemotherapy resistance in leukemia cells. Leukemia. 2011;25(1):23-31.

176. Lundbäck P, Lea JD, Sowinska A, Ottosson L, Fürst CM, Steen J, et al. A novel high mobility group box 1 neutralizing chimeric antibody attenuates drug-induced liver injury and postinjury inflammation in mice. Hepatology (Baltimore, Md). 2016;64(5):1699-710.

177. Watanabe H, Watanabe KS, Liu K, Hiramatsu S, Zeggar S, Katsuyama E, et al. Anti-high Mobility Group Box 1 Antibody Ameliorates Albuminuria in MRL/
Ipr Lupus-Prone Mice. Molecular therapy Methods \& clinical development. 2017:6:31-9.

178. Schierbeck H, Lundbäck P, Palmblad K, Klevenvall L, Erlandsson-Harris H, Andersson $U$, et al. Monoclonal anti-HMGB1 (high mobility group box chromosomal protein 1) antibody protection in two experimental arthritis models. Molecular medicine (Cambridge, Mass). 2011;17(9-10):1039-44.

179. Yan W, Chang Y, Liang X, Cardinal JS, Huang H, Thorne SH, et al. Highmobility group box 1 activates caspase-1 and promotes hepatocellular carcinoma invasiveness and metastases. Hepatology (Baltimore, Md). 2012; 55(6):1863-75

180. Hwang YH, Kim MJ, Lee YK, Lee M, Lee DY. HMGB1 modulation in pancreatic islets using a cell-permeable A-box fragment. Journal of controlled release: official journal of the Controlled Release Society. 2017;246:155-63.

181. Smolarczyk R, Cichoń T, Matuszczak S, Mitrus I, Lesiak M, Kobusińska M, et al. The role of Glycyrrhizin, an inhibitor of HMGB1 protein, in anticancer therapy. Arch Immunol Ther Exp. 2012;60(5):391-9.

182. Kim SW, Jin Y, Shin JH, Kim ID, Lee HK, Park S, et al. Glycyrrhizic acid affords robust neuroprotection in the postischemic brain via anti-inflammatory effect by inhibiting HMGB1 phosphorylation and secretion. Neurobiol Dis. 2012:46(1):147-56

183. Shin JH, Kim ID, Kim SW, Lee HK, Jin Y, Park JH, et al. Ethyl pyruvate inhibits HMGB1 phosphorylation and release by chelating calcium. Molecular medicine (Cambridge, Mass). 2015;20(1):649-57.

184. Seo MS, Kim HJ, Kim H, Park SW. Ethyl pyruvate directly attenuates active secretion of HMGB1 in proximal tubular cells via induction of heme oxygenase-1. J Clin Med. 2019:8:5.

185. Liu Q, Huo Y, Zheng H, Zhao J, Jia L, Wang P. Ethyl pyruvate suppresses the growth, invasion and migration and induces the apoptosis of non-small cell lung cancer cells via the HMGB1/RAGE axis and the NF-kB/STAT3 pathway. Oncol Rep. 2019;42(2):817-25.

186. Dhumale SS, Waghela BN, Pathak C. Quercetin protects necrotic insult and promotes apoptosis by attenuating the expression of RAGE and its ligand HMGB1 in human breast adenocarcinoma cells. IUBMB Life. 2015;67(5):361-73.

187. Kim YH, Kwak MS, Shin JM, Hayuningtyas RA, Choi JE, Shin JS. Inflachromene inhibits autophagy through modulation of Beclin 1 activity. J Cell Sci. 2018;131:4.

188. Quan H, Bae HB, Hur YH, Lee KH, Lee $\mathrm{CH}$, Jang EA, et al. Stearoyl lysophosphatidylcholine inhibits LPS-induced extracellular release of HMGB1 through the G2AVcalcium/CaMKKB/AMPK pathway. Eur J Pharmacol. 2019;852:125-33.

189. Sun S, He M, Wang Y, Yang H, Al-Abed Y. Folic acid derived-P5779 mimetics regulate DAMP-mediated inflammation through disruption of HMGB1:TLR4: MD-2 axes. PLoS One 2018:13(2):e0193028.

190. Inoue Y, Saito T, Ogawa K, Nishio Y, Kosugi S, Suzuki Y, et al. Role of serum high mobility group box 1 in hematological malignancies complicated with systemic inflammatory response syndrome and effect of recombinant thrombomodulin. Leuk Lymphoma. 2013;54(9):1953-8.

191. Nomura S, Fujita S, Ozasa R, Nakanishi T, Miyaji M, Mori S, et al. The correlation between platelet activation markers and HMGB1 in patients with disseminated intravascular coagulation and hematologic malignancy. Platelets. 2011:22(5):396-7.

192. Ookura M, Hosono N, Tasaki T, Oiwa K, Fujita K, Ito K, et al. Successful treatment of disseminated intravascular coagulation by recombinant human soluble thrombomodulin in patients with acute myeloid leukemia. Medicine. 2018;97(44):e12981

193. Hagiwara S, Iwasaka H, Matsumoto S, Hasegawa A, Yasuda N, Noguchi T. In vivo and in vitro effects of the anticoagulant, thrombomodulin, on the inflammatory response in rodent models. Shock (Augusta, Ga). 2010:33(3):282-8.

194. Shirai Y, Uwagawa T, Shiba H, Shimada Y, Horiuchi T, Saito N, et al. Recombinant thrombomodulin suppresses tumor growth of pancreatic cancer by blocking thrombin-induced PAR1 and NF-KB activation. Surgery. 2017:161(6):1675-82.

\section{Publisher's Note}

Springer Nature remains neutral with regard to jurisdictional claims in published maps and institutional affiliations. 